\title{
Spatial distribution analysis of the OMI aerosol layer height: a pixel-by-pixel comparison to CALIOP observations
}

\author{
Julien Chimot $^{1, \mathrm{a}}$, J. Pepijn Veefkind ${ }^{1,2}$, Tim Vlemmix ${ }^{2}$, and Pieternel F. Levelt ${ }^{1,2}$ \\ ${ }^{1}$ Department of Geoscience and Remote Sensing (GRS), Civil Engineering and Geosciences, TU Delft, the Netherlands \\ ${ }^{2}$ Royal Netherlands Meteorological Institute, De Bilt, the Netherlands \\ anow at: European Organisation for the Exploitation of Meteorological Satellites (EUMETSAT), Darmstadt, Germany
}

Correspondence: Julien Chimot (julien.chimot@eumetsat.int)

Received: 26 October 2017 - Discussion started: 7 November 2017

Revised: 17 March 2018 - Accepted: 22 March 2018 - Published: 19 April 2018

\begin{abstract}
A global picture of atmospheric aerosol vertical distribution with a high temporal resolution is of key importance not only for climate, cloud formation, and air quality research studies but also for correcting scattered radiation induced by aerosols in absorbing trace gas retrievals from passive satellite sensors. Aerosol layer height (ALH) was retrieved from the OMI $477 \mathrm{~nm} \mathrm{O}_{2}-\mathrm{O}_{2}$ band and its spatial pattern evaluated over selected cloud-free scenes. Such retrievals benefit from a synergy with MODIS data to provide complementary information on aerosols and cloudy pixels. We used a neural network approach previously trained and developed. Comparison with CALIOP aerosol level 2 products over urban and industrial pollution in eastern China shows consistent spatial patterns with an uncertainty in the range of $462-648 \mathrm{~m}$. In addition, we show the possibility to determine the height of thick aerosol layers released by intensive biomass burning events in South America and Russia from OMI visible measurements. A Saharan dust outbreak over sea is finally discussed. Complementary detailed analyses show that the assumed aerosol properties in the forward modelling are the key factors affecting the accuracy of the results, together with potential cloud residuals in the observation pixels. Furthermore, we demonstrate that the physical meaning of the retrieved ALH scalar corresponds to the weighted average of the vertical aerosol extinction profile. These encouraging findings strongly suggest the potential of the OMI ALH product, and in more general the use of the $477 \mathrm{~nm} \mathrm{O} \mathrm{O}_{2}-\mathrm{O}_{2}$ band from present and future similar satellite sensors, for climate studies as well as for future aerosol correction in air quality trace gas retrievals.
\end{abstract}

\section{Introduction}

Aerosols are small particles suspended in the air (e.g. desert dust, sea salt, volcanic ashes, sulfate, nitrate, and smoke from biomass and fossil-fuel burning). Aerosol sources and sinks are heterogeneously distributed. Due to their scattering and absorption effects on solar and thermal radiation, they redistribute shortwave radiation in the atmosphere. Their presence not only perturbs the air thermal state and stability, our climate system, air quality, and meteorological conditions but also interferes with satellite observations of atmospheric trace gases. Aerosols are an important player in the climate system by leading to atmospheric warming, surface cooling, and additional atmospheric dynamical responses (IPCC: The Core Writing Team Pachauri and Meyer, 2014). By acting as the condensation nuclei on which clouds form, they also modify cloud formation, lifetime, and precipitation (Figueras i Ventura and Russchenberg, 2009; Sarna and Russchenberg, 2017). Overall, the climate effects of aerosols are large, but the scientific understanding of their effects remains challenging as their radiative properties is one of the main uncertain components in global climate models (Yu et al., 2006; IPCC: The Core Writing Team Pachauri and Meyer, 2014). Finally, the scattering and absorption by aerosols impact the actinic flux and consequently modify the photolysis rates of important processes in the atmosphere (Palancar et al., 2013).

In addition, scattering and absorption of shortwave radiation by aerosols modify the average light path in the atmosphere and therefore interfere with satellite observations of gases, such as $\mathrm{NO}_{2}, \mathrm{SO}_{2}, \mathrm{O}_{3}, \mathrm{CO}_{2}$, and $\mathrm{CH}_{4}$, which are important for air quality and climate science objectives. Europe 
is heavily investing in the development of polar-orbiting and geostationary satellite systems in the Copernicus program (Ingmann et al., 2012), which will form an important component of air quality and climate observing systems on urban, regional, and global scales (Martin, 2008; Duncan et al., 2014). However, inaccurate aerosol correction on these satellite measurements leads to misinterpretations and incorrect evaluations of the implemented emission regulation controls.

The magnitude of the radiative forcing by aerosols depends on the environmental conditions, aerosol properties, and horizontal and vertical distribution (IPCC: The Core Writing Team Pachauri and Meyer, 2014; Kipling et al., 2016). Its determination requires satellite data in addition to models (IPCC: The Core Writing Team Pachauri and Meyer, 2014). While, overall, the horizontal distributions of aerosol optical depth (AOD or $\tau$ ) and size are relatively well constrained, uncertainties in vertical profile significantly contribute to the overall uncertainty of radiative effects: e.g. $25 \%$ of the uncertainty of black carbon radiative estimations from the models is related to an inaccurate knowledge on the vertical distribution (McComiskey et al., 2008; Loeb and Su, 2010; Zarzycki and Bond, 2010; IPCC: The Core Writing Team Pachauri and Meyer, 2014). Knowledge of aerosol vertical profiles allows the computation of related heating rates: e.g. particles located above clouds can increase the liquid water path and geometric thickness of clouds and the subsequent atmospheric heating, and advection of light-absorbing aerosols over the ocean and clouds from rice straw burning in China can strongly reduce clouds and Earth radiant energy (Hsu et al., 2003; de Graaf et al., 2012; Wilcox, 2012). Therefore, aerosol layer height (ALH) drives not only the magnitude but also the sign of aerosol direct and indirect radiative effects (Kipling et al., 2016). Current ALH simulated by climate models can differ in the range of $1.5-3 \mathrm{~km}$ (Koffi et al., 2012; Kipling et al., 2016).

Furthermore, in the absence of clouds, vertical distribution of aerosols is one of the most significant error sources in trace gas retrievals from satellites (Leitão et al., 2010; Chimot et al., 2016). Major biases on the pollutant tropospheric $\mathrm{NO}_{2}$ measured by satellites, depending on AOD and $\mathrm{ALH}$, can be expected if no aerosol correction is applied. Because such information is not available for every observation, aerosols are approximated via a simple cloud model (Acarreta et al., 2004; Boersma et al., 2011; Veefkind et al., 2016). This only leads to a first-order correction for short-lived gases $\left(\mathrm{NO}_{2}, \mathrm{SO}_{2}\right.$, and $\left.\mathrm{HCHO}\right)$ that does not comprehensively assume the full scattering and absorbing effects of aerosol particles on the average light path followed by the detected photons (Boersma et al., 2011; Chimot et al., 2016). In particular, current uncertainties on ALH lead to substantial biases in areas with high AOD $(\tau(550 \mathrm{~nm}) \geq 0.5)$ and absorbing and elevated particles: between -26 and $-40 \%$ on the retrieved tropospheric $\mathrm{NO}_{2}$ columns from the Dutch-Finnish Ozone Monitoring Instrument (OMI) (Castellanos et al., 2015; Chimot et al., 2016), 20-50\% on Global Ozone Mon- itoring Experiment-2 (GOME-2) and SCIAMACHY HCHO (Barkley et al., 2012; Hewson et al., 2015), and about 50\% on OMI SO 2 (Krotkov et al., 2008). ALH also remains one of the largest error sources for greenhouse gas retrievals: e.g. $\mathrm{CO}_{2}$ from the American carbon OCO-2 mission (Crisp, 2015; Connor et al., 2016; Wunch et al., 2017) and $\mathrm{CH}_{4}$ from the future TROPOMI on board Sentinel-5 Precursor (Hu et al., 2016).

Consequently, determining ALH with a large coverage (ideally daily and global) and an uncertainty better than $1 \mathrm{~km}$ (as a first approximation), for every single absorbing trace gas atmospheric satellite pixel, is ideally needed. Active satellite sensors, such as the Cloud-Aerosol Lidar with Orthogonal Polarization (CALIOP), allow us to probe detailed vertical aerosol profile, but with a limited coverage as they only look towards the nadir. This can lead to a gap up to $2200 \mathrm{~km}$ (in the tropics and subtropics) between adjacent orbital tracks. As an alternative, passive satellite sensors, with a high spectral resolution such as OMI, offer adequate spatial coverage with a good temporal resolution (up to daily global before the OMI row anomaly development) thanks to a wide swath. Thus, passive hyperspectral instruments can provide great contribution even if they do not achieve the same level of accuracy as active instruments (i.e. limited vertical resolution, only cloud-free scenes). Because molecular oxygen $\left(\mathrm{O}_{2}\right)$ is well mixed, its slant column measurement provides a suitable proxy for the determination of the modified scattering height due to aerosols, in the absence of clouds. Most of the developed ALH retrieval algorithms from backscattered sunlight satellite measurements focus on the absorption spectroscopy of the $\mathrm{O}_{2}$ A band around $765 \mathrm{~nm}$, relatively close to the $\mathrm{CO}_{2}$ and $\mathrm{CH}_{4}$ absorption bands (Wang et al., 2012; Sanders et al., 2015). Some studies also focus on the use of the $\mathrm{O}_{2}$ B band (Ding et al., 2016; Xu et al., 2017). So far, only a few studies have worked on using the $\mathrm{O}_{2}-\mathrm{O}_{2}$ satellite absorption bands, within the ultraviolet (UV) and visible (vis) spectral ranges, to retrieve ALH and $\tau$ (Park et al., 2016; Chimot et al., 2017). These bands are spectrally closer to the $\mathrm{NO}_{2}, \mathrm{SO}_{2}$, and $\mathrm{HCHO}$ absorption lines. Contrary to the $\mathrm{O}_{2}$ A band, the $\mathrm{O}_{2}-\mathrm{O}_{2} 477 \mathrm{~nm}$ band presents a wider (over $10 \mathrm{~nm}$ ) but weaker spectral absorption. This leads to high sensitivities in the case of strong aerosol loading and less challenges due to saturation. Moreover, in the visible spectral range, AOD values are generally higher while surface albedo or reflectance is lower, leading to a higher contrast between aerosol and surface scattering signals. The $477 \mathrm{~nm} \mathrm{O} \mathrm{O}_{2}-\mathrm{O}_{2}$ channel is not only present in the current GOME-2, OMI, and TROPOMI satellite sensors, but will be also included in future Sentinel-4 and Sentinel-5 instruments (Ingmann et al., 2012; Veefkind et al., 2012).

This paper follows the exploratory study of Chimot et al. (2017), in which a neural network (NN) algorithm was developed to investigate the feasibility of deriving ALH from the OMI $477 \mathrm{~nm} \mathrm{O} \mathrm{O}_{2}-\mathrm{O}_{2}$ spectral band over cloud-free scenes. The main objective was the study of anthropogenic particles 
emission and their precursors from vehicles, coal burning, and industries. It has allowed us to retrieve ALH over land for the first time from this specific spectral band. A statistic evaluation of 3-year cloud-free OMI observations over eastern Asia, focusing on urban and large industrialized areas, has shown maximum differences below $800 \mathrm{~m}$ with a reference climatology database. In order to complete this first and statistically focused evaluation, the present study evaluates the spatial distribution of the OMI $477 \mathrm{~nm} \mathrm{O}_{2}-\mathrm{O}_{2} \mathrm{ALH}$ product on a pixel-by-pixel basis. It therefore focuses on its variability for single days. For that purpose, specific cloudfree case studies are selected, including 3 winter days with strong anthropogenic pollution over eastern China. In addition, to extend the performance assessment of such an approach beyond the initial objective of Chimot et al. (2017), new types of aerosol pollution episodes are investigated: 4 summer days with large biomass burning events in South America and east of Russia and 1 day of wide desert dust transport over sea. The OMI ALH retrieval is compared with the collocated CALIOP level 1 (L1) measurements and level 2 (L2) aerosol retrievals.

\section{OMI, MODIS, and CALIOP aerosol observations}

\subsection{The OMI sensor and $\mathrm{O}_{2}-\mathrm{O}_{2} 477 \mathrm{~nm}$ spectral band}

The Dutch-Finnish OMI mission (Levelt et al., 2006) is a nadir-viewing push-broom imaging spectrometer launched on the National Aeronautics and Space Administration (NASA) Earth Observing System (EOS) Aura satellite. It delivers global coverage with a high temporal resolution of key air quality components derived from measurements of the backscattered solar radiation acquired in the UV-vis spectral domain $(270-550 \mathrm{~nm})$ with approximately $0.5 \mathrm{~nm}$ resolution. Based on a two-dimensional detector array concept, radiance spectra are simultaneously measured on a $2600 \mathrm{~km}$ wide swath within a nadir pixel size of $13 \times 24 \mathrm{~km}^{2}\left(28 \times 150 \mathrm{~km}^{2}\right.$ at extreme off-nadir).

The $\mathrm{O}_{2}-\mathrm{O}_{2} 477 \mathrm{~nm}$ absorption band is currently operationally exploited by the $\mathrm{OMI} \mathrm{O}_{2}-\mathrm{O}_{2}$ cloud algorithm (OMCLDO2) to derive effective cloud parameters (Acarreta et al., 2004; Veefkind et al., 2016). This spectral band directly measures the absorption of the visible part of the sunlight induced by the $\mathrm{O}_{2}-\mathrm{O}_{2}$ collision complex along the whole light path. A spectral fit, prior to the OMI effective cloud retrieval algorithm, is performed over the $460-490 \mathrm{~nm}$ spectral range to derive the continuum reflectance $R_{\mathrm{c}}(475 \mathrm{~nm})$ and the $\mathrm{O}_{2}-\mathrm{O}_{2}$ slant column density $N_{\mathrm{O}_{2}-\mathrm{O}_{2}}^{\mathrm{s}}$. This spectral fit relies on the differential optical absorption spectroscopy (DOAS) approach (Platt and Stutz, 2008). $N_{\mathrm{O}_{2}-\mathrm{O}_{2}}^{\mathrm{s}}$ represents the $\mathrm{O}_{2}-\mathrm{O}_{2}$ absorption magnitude along the average light path through the atmosphere. This is the key input variable for the OMI ALH retrieval by the NN algorithm.

\subsection{The OMI aerosol layer height neural network algorithm}

The OMI ALH retrieval algorithm (Chimot et al., 2017) is based on the exploitation of $N_{\mathrm{O}_{2}-\mathrm{O}_{2}}^{\mathrm{s}}$ derived from the DOAS fit and relies on a NN approach. Here, the main elements of this algorithm are summarized, but for more details about their technical development and implementation, see Chimot et al. (2017).

This algorithm relies on how aerosols affect the length of the average light path along which the $\mathrm{O}_{2}-\mathrm{O}_{2}$ absorbs. $N_{\mathrm{O}_{2}-\mathrm{O}_{2}}^{\mathrm{s}}$ is then driven by the overall shielding or enhancement effect of photons by the $\mathrm{O}_{2}-\mathrm{O}_{2}$ complex in the visible spectral range due to the presence of particles. An aerosol layer located at high altitudes applies a large shielding effect on the $\mathrm{O}_{2}-\mathrm{O}_{2}$ located in the atmospheric layers below: i.e. the amount of photons coming from the top of the atmosphere (TOA) and reaching the lowest part of the atmosphere is reduced compared to an aerosol-free scene. This shielding effect is then larger when the aerosol layer is located at an elevated altitude than close to the surface.

The designed NNs belong to the family of machine learning and the artificial intelligence domain and rely on a multilayer architecture, also named multilayer perceptron. The input and output variables are interconnected through a set of sigmoid functions present in the hidden layers and the synaptic weights $W$. For each single sigmoid function, two simple operations are performed: (1) a weighted sum of all the inputs given by the previous layer and (2) a transport of this sum through the sigmoid functions. The ALH retrieval problem then becomes a simple series of analytical functions.

For all the processed OMI scenes, aerosol profile is assumed as one single scattering layer (also called "box layer") with a constant geometric thickness $(100 \mathrm{hPa}$, or about $1 \mathrm{~km})$. The particles included in this layer are homogeneous (i.e. same size and optical properties). ALH is then defined as the mid-altitude (a.s.l.) of this scattering layer. Furthermore, aerosol particles are assumed to cover the entire satellite observation pixel. The input layer contains seven parameters: viewing zenith angle $\theta$, solar zenith angle $\theta_{0}$, relative azimuth angle $\phi_{r}$, surface pressure $P s$, surface albedo $A$, aerosol optical thickness $\tau(550 \mathrm{~nm})$, and the $\mathrm{OMI} N_{\mathrm{O}_{2}-\mathrm{O}_{2}}^{\mathrm{s}}$. As explained in Chimot et al. (2017), a prior $\tau(550 \mathrm{~nm})$ is required as input as both ALH and $\tau(550 \mathrm{~nm})$ simultaneously affect $N_{\mathrm{O}_{2}-\mathrm{O}_{2}}^{\mathrm{s}}$ and need to be distinguished.

The optimal weights were estimated through a rigorous training task following the error back propagation technique and a training dataset that includes a set of representative situations for which inputs and outputs are well known. The quality of the training dataset was ensured by full physical spectral simulations, dominated by aerosol particles without clouds, generated by the Determining Instrument Specifications and Analyzing Methods for Atmospheric Retrieval (DISAMAR) software of KNMI (de Haan, 2011). Aerosol scattering is simulated by a Henyey-Greenstein (HG) scat- 
tering phase function $\Phi(\Theta)$ parameterized by the asymmetry parameter $g$, which is the average of the cosine of the scattering angle (Hovenier and Hage, 1989). Aerosols were specified for a standard case, assuming fine particles with a unique value of the extinction Ångström exponent $\alpha=1.5$ and $g=0.7$. In order to investigate the assumptions related to the aerosol single scattering albedo $\omega_{0}$ properties, two training datasets were generated with a different typical value: one with $\omega_{0}=0.95$ and one with $\omega_{0}=0.9$ in the visible spectral domain. Therefore, two OMI ALH NN algorithms were created, one for each aerosol $\omega_{0}$ values.

The aerosol models in the training database were based on a HG scattering phase function for two reasons. First, both Chimot et al. (2017) and this paper are exploratory studies focusing on the potential of exploiting the $\mathrm{O}_{2}-\mathrm{O}_{2}$ spectral band for aerosol retrievals from a satellite sensor. Second, our first long-term objective is the potential use of the ALH parameter for future tropospheric $\mathrm{NO}_{2}$ and similar trace gas retrievals over cloud-free scenes. Several studies emphasized that ALH is the key variable affecting the length of the average light path in the computation of the related air mass factor (AMF) computation through the DOAS approach (Boersma et al., 2004; Castellanos et al., 2015; Chimot et al., 2016). This is because the only quantity that is relevant for absorption by trace gases in the visible is the average light path distribution, i.e. the distribution of distances travelled by photons in the atmosphere before leaving the atmosphere. The absolute radiance at the TOA is less important. The second variable of interest is $\tau$. This average light path distribution is mostly governed by $\omega_{0}$ and $g$, and of course ALH and $\tau$, and much less by details in the phase function. Studies by Leitão et al. (2010), Castellanos et al. (2015), and Chimot et al. (2016) showed the lower sensitivity of the AMF to $\alpha$, $\omega_{0}$, and $g$. These scattering parameters are included in HG scattering, and therefore this parameterized phase function can be used for AMF calculations. At this level and with respect to these mentioned objectives, it is then assumed one does not need to define more realistic aerosol models for every single OMI pixel. With $g=0.7$, the HG function is known to be smooth and reproduce the Mie scattering functions reasonably well for most of aerosol types, in particular for spherical particles (e.g. nitrate, sulfate) (Dubovik et al., 2002). Such an approach is used for the preparation of the operational ALH retrieval algorithms for Sentinel-4 and Sentinel-5 Precursor (Leitão et al., 2010; Sanders et al., 2015; Colosimo et al., 2016; Nanda et al., 2018) and for various explicit aerosol corrections in the AMF calculation when retrieving trace gases, such as tropospheric $\mathrm{NO}_{2}$, over urban and industrial areas dominated by anthropogenic pollution, for example in eastern China (Spada et al., 2006; Wagner et al., 2007; Castellanos et al., 2015; Vlemmix et al., 2010). The potential impact of the modelled scattering phase discussion is kept in mind and further discussed in Sect. 4.4. However, reperforming the whole NN training process with more complex particle shape models is computationally very demanding and beyond the scope of this paper. Instead, more elements on specific error analysis are further discussed in Sect. 4.

Maximum seasonal differences between the LIdar climatology of Vertical Aerosol Structure for space-based lidar simulation studies (LIVAS) and 3-year OMI ALH, over cloud-free scenes in north-eastern Asia with MODIS $\tau(550 \mathrm{~m}) \geq 1.0$, are in the range of $180-800 \mathrm{~m}$ (Amiridis et al., 2015; Chimot et al., 2017). The previous extended sensitive study has shown the following. (a) Due to the nature of the $\mathrm{O}_{2}-\mathrm{O}_{2}$ spectral band, a minimum particle load (i.e. $\tau(550 \mathrm{~nm})=0.5)$ is required to be able to exploit the aerosol signal as, below this threshold, low amounts of aerosols have negligible impacts on $\mathrm{N}_{\mathrm{O}_{2}-\mathrm{O}_{2}}^{\mathrm{s}}$ shielding and lead to high ALH bias. (b) The aerosol model assumptions are the most critical, in particular $\omega_{0}$, as they may affect ALH retrieval uncertainty up to $660 \mathrm{~m}$. (c) In addition, potential aerosol residuals in the prior surface albedo may impact up to $200 \mathrm{~m}$. (d) An accuracy of 0.2 is required on prior $\tau(550 \mathrm{~nm})$ to limit ALH bias close to zero when $\tau(550 \mathrm{~nm}) \geq 1.0$ and below $500 \mathrm{~m}$ for $\tau(550 \mathrm{~nm})$ values close to 0.6 .

\subsection{The CALIOP and MODIS aerosol products}

CALIOP sensor is a standard dual-wavelength elastically backscattered lidar on board the CALIPSO satellite platform, flying since 2006. Equipped with a depolarization channel at $532 \mathrm{~nm}$, it probes the aerosol and cloud vertical layers, from the surface to $40 \mathrm{kma}$ a.s.l., with a high vertical resolution (Winker et al., 2009). Level 1 scientific data products, distributed by the Atmospheric Science Data Center (ASDC) of NASA, include the lidar calibrated and geolocated measurements of high-resolution vertical profiles (between 30 and $60 \mathrm{~m}$ in the troposphere) of the aerosol and cloud attenuated backscatter coefficients at 532 and $1064 \mathrm{~nm}$ with horizontal resolutions of $1 / 3,1$, and $5 \mathrm{~km}$ (Winker et al., 2009).

The CALIOP aerosol L2 product contains the retrieved aerosol backscatter and extinction coefficient profiles at 532 and $1064 \mathrm{~nm}$, for each identified and well-located aerosol layer, at $5 \mathrm{~km}$ horizontal resolution. These retrievals are performed after calibration, range correction, feature detection and classification, and assumptions on lidar extinctionto-backscattering ratio (Winker et al., 2009; Young and Vaughan, 2009).

The MODIS spectrometer was launched on the NASA EOS Aqua platform in May 2002 and has been delivering continuous images of the Earth in the visible, solar, and thermal infrared approximately 15 min prior to OMI. The considered Aqua MODIS L2 aerosol product is the Collection 6 of MYD04_L2, based on the Dark Target (DT) and Deep Blue (DB) algorithms with a high enough quality assurance flag and an improved calibration of the instrument (Levy et al., 2013). While the MODIS measurement is acquired at the resolution of $1 \mathrm{~km}$, the used MODIS aerosol $\tau(550 \mathrm{~nm})$ is at $10 \mathrm{~km} \times 10 \mathrm{~km}$, relatively close to the OMI nadir spatial 

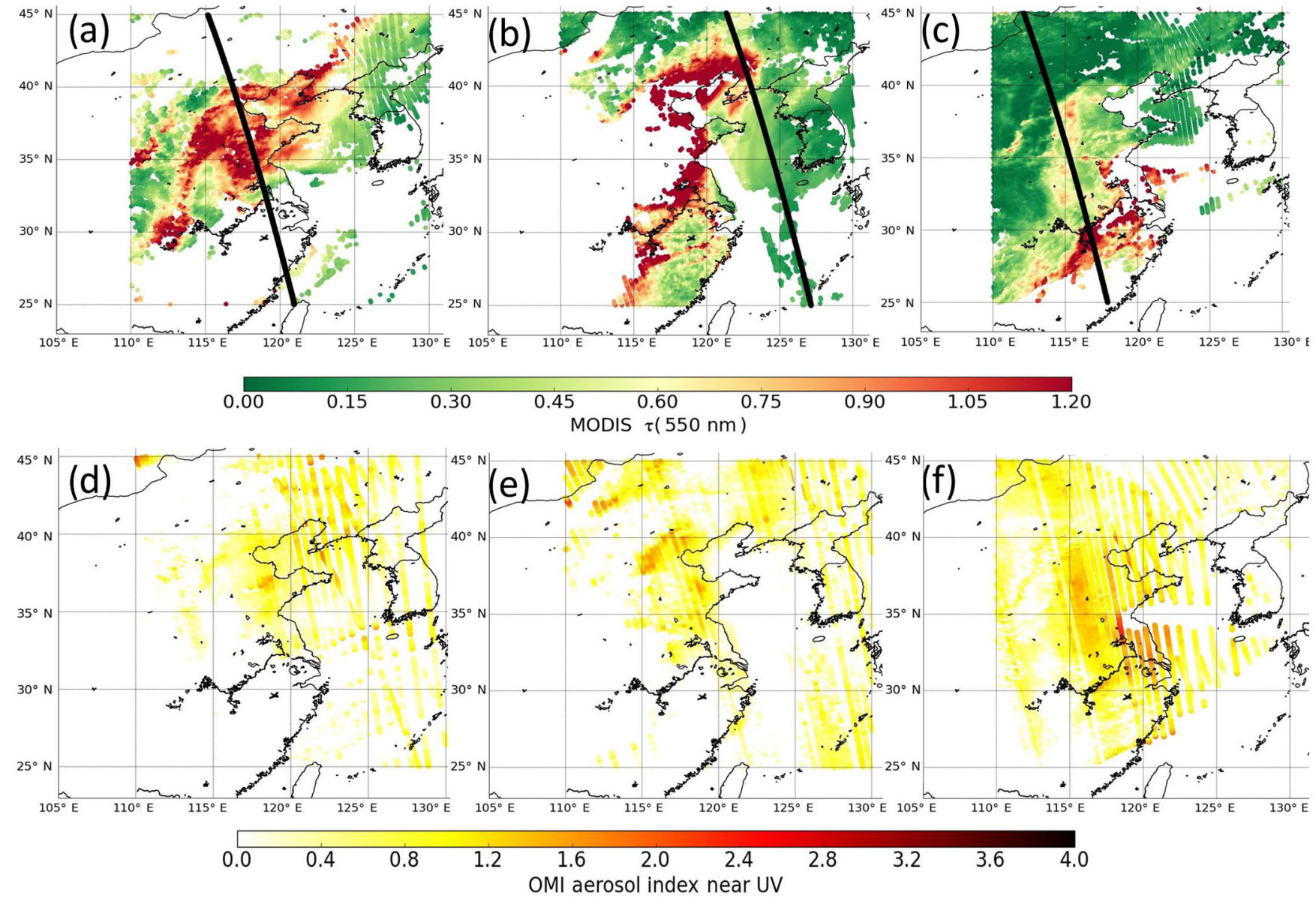

Figure 1. Maps of Aqua MODIS $\tau(550 \mathrm{~nm}$ ) from the combined DT and DB Collection 6 (see Sect. 2.3) and collocated OMI aerosol index from near-UV (UVAI) values (see Sect. 3) over cloud-free scenes for the urban and industrialized cases in eastern China. The dark thick lines represent the track of CALIPSO space-borne sensor over the selected case studies: (a, d) 2 October 2006, (b, e) 6 October 2006, and (c, f) 1 November 2006.

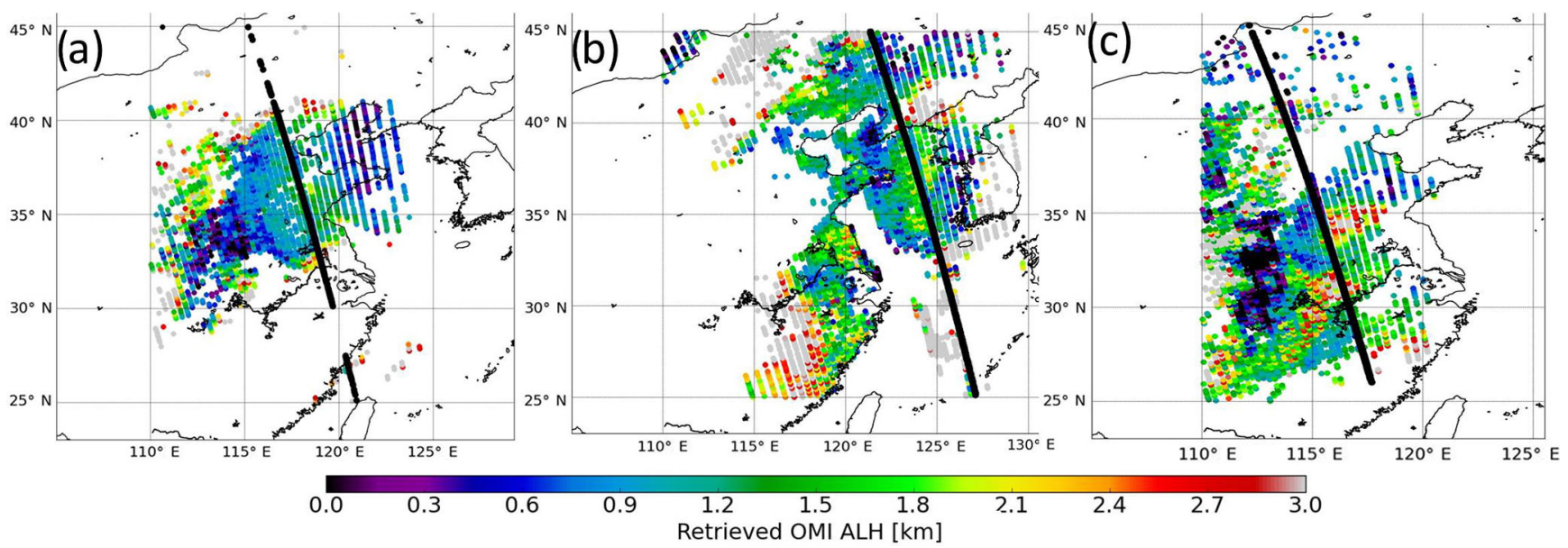

Figure 2. Maps of retrieved OMI aerosol layer height (ALH) from all the cloud-free pixels collocated with Aqua MODIS $\tau$ (550 nm) (see Fig. 1). The dark thick lines represent the track of CALIPSO space-borne sensor over the selected case studies: (a) 2 October 2006, (b) 6 October 2006, and (c) 1 November 2006. 
resolution. The expected uncertainties of MODIS $\tau(550 \mathrm{~nm})$ are about $\pm 0.05+15 \%$ over land for DT (Levy et al., 2013) and about \pm 0.03 on average for DB (Sayer et al., 2013).

\section{Case studies: results and discussion}

\subsection{Methodology}

OMI ALH retrievals are here obtained using MODIS L2 aerosol $\tau(550 \mathrm{~nm})$ from the combined DT and DB product as prior input, collocated within a distance of $15 \mathrm{~km}$ and where $\tau(550 \mathrm{~nm}) \geq 0.55$ (see Sect. 2.2). Mitigating the probability of cloud contamination within the OMI pixel is one of the first criteria for a successful ALH retrieval. For that purpose, we rely on the availability of the MODIS aerosol product with the highest quality assurance flag ensuring that Aqua MODIS $\tau(550 \mathrm{~nm})$ is exclusively estimated when a sufficient high amount of cloud-free sub-pixels is available (i.e. at the MODIS measurement resolution of $1 \mathrm{~km}$ ) (Levy et al., 2013). However, since this may be not completely representative of the atmospheric situation of the OMI pixel, two thresholds are added for each collocated OMI-MODIS pixel: the geometric MODIS cloud fraction to be smaller than 0.1, and the effective OMI cloud fraction lower than 0.2. For this last parameter, it was shown that values higher than 0.3 are generally likely contaminated by clouds, while values between 0.1 and 0.2 may be cloud-free but contain a substantial amount of very scattered particles that increase the scene brightness (Boersma et al., 2011; Chimot et al., 2016).

The ALH retrievals are applied to the OMI DOAS $\mathrm{O}_{2}-\mathrm{O}_{2}$ observations, available in the last reprocessed OMCLDO2 product version (Acarreta et al., 2004; Veefkind et al., 2016). A temperature correction is taken into account on the $N_{\mathrm{O}_{2}-\mathrm{O}_{2}}^{\mathrm{s}}$ variable, using the information available in the OMCLDO2 product, which is itself based on the temperature profiles of the National Centers for Environmental Prediction (NCEP) analysis data (Veefkind et al., 2016).

The selected case studies include (1) urban and industrial aerosol pollution over eastern China during 3 days between October and November 2006, (2) large wildfire episodes in South America in August 2006 and September 2007 and in eastern Russia in August 2010 and June 2012, and (3) a Saharan dust transport over sea in June 2012. OMI ALH retrievals are compared with collocated CALIOP products within a distance of $50-100 \mathrm{~km}$ for the cases over eastern China and South America and $300 \mathrm{~km}$ for eastern Russia. The larger OMI-CALIOP distance over these two last regions is due to the so-called "row anomaly", which has been significantly perturbing OMI measurements of the earthshine radiance at all wavelengths since 2009. This leads to a reduced number of valid OMI ground pixels close to the CALIOP track. Details are given at http://www.knmi.nl/omi/research/product/ rowanomaly-background.php (last access: 8 August 2010).
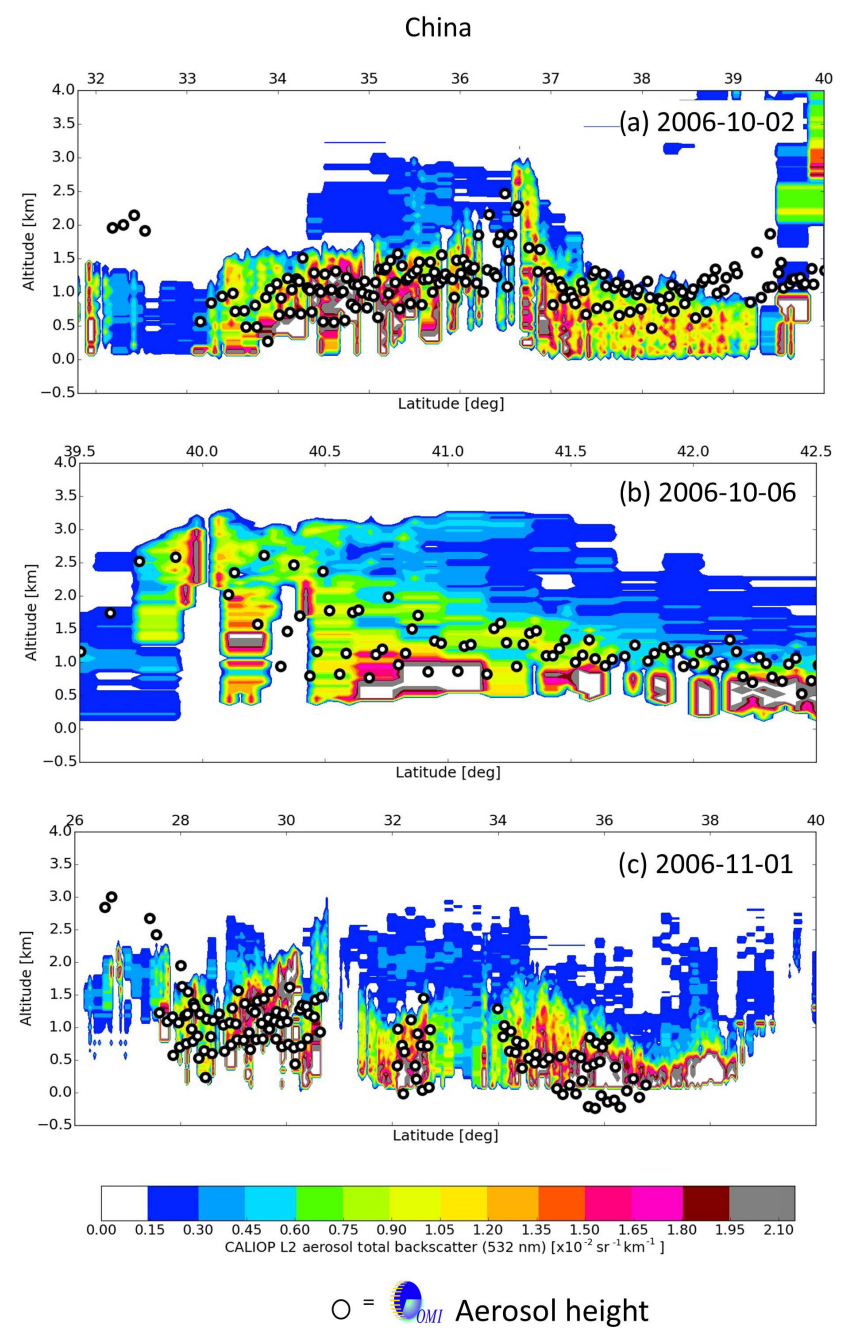

Figure 3. Retrieved OMI ALH compared with vertical profile of aerosol total backscatter coefficient $(532 \mathrm{~nm})$ from the CALIOP L2 product. Maximal distance between OMI pixels and CALIOP ground track is $50 \mathrm{~km}$. Only cloud-free OMI pixels, collocated with Aqua MODIS Collection 6 aerosol cells, $\tau(550 \mathrm{~nm}) \geq 0.55$ (from the MODIS DT and DB algorithms), are selected: (a) 2 October 2006, (b) 6 October 2006, and (c) 1 November 2006.

For each study case, the most likely suitable NN algorithm (see Sect. 2.2) is selected by hand. We decided to rely on (1) the OMI UV aerosol absorbing index (UVAI) and (2) their well-known absorbing properties (according to the literature) in the visible spectral range in order to approximate the assumption on aerosol $\omega_{0}$ at the visible $(460-490 \mathrm{~nm}) \mathrm{spec}-$ tral wavelengths. OMI UVAI is derived by the OMI near-UV aerosol algorithm (OMAERUV) in the $330-388 \mathrm{~nm}$ spectral band (Torres et al., 2007). It allows us to detect and distinguish UV absorbing from scattering aerosols through the measured change of spectral contrast, with respect to a pure Rayleigh atmosphere. Weakly absorbing or large nonabsorbing particles are associated with near-zero or negative UVAI values. A threshold of 1 on UVAI is then specified to 

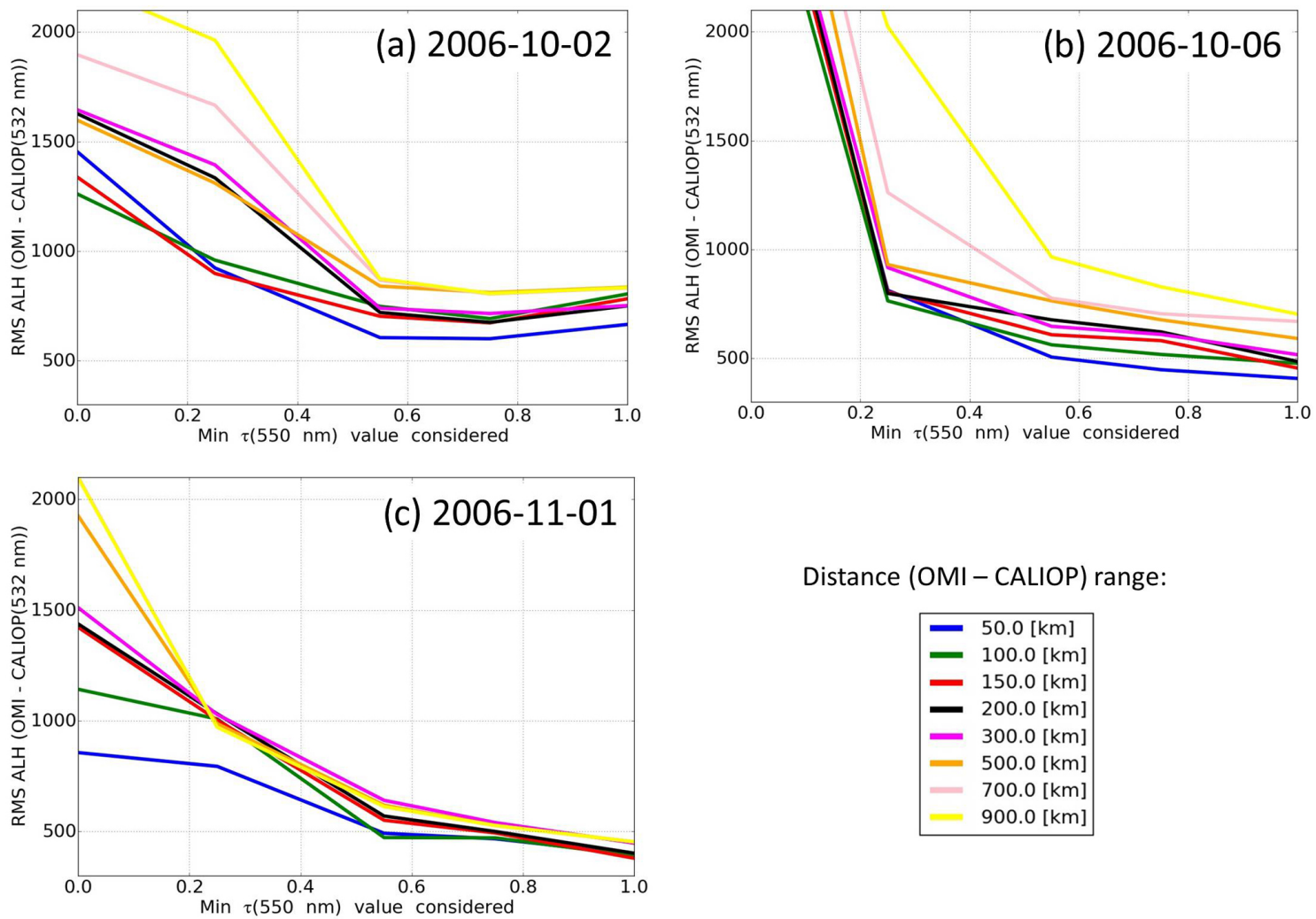

Distance (OMI - CALIOP) range:

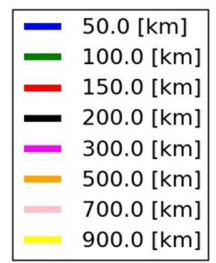

Figure 4. Root-mean-square (RMS) deviation between collocated retrieved OMI ALH and derived CALIOP ALH (532 nm) (see Sect. 4.1) for urban and industrialized cases over eastern China as a function of minimum MODIS $\tau(550 \mathrm{~nm})$ and distance between OMI and CALIOP ground pixels: (a) 2 October 2006, (b) 6 October 2006, and (c) 1 November 2006.

detect absorbing particles in the UV and then potentially in the visible.

\subsection{Urban aerosol pollution}

Fossil-fuel combustion is the main source of air pollution in the large urban and industrialized area of eastern China. With decreasing temperatures in autumn, coal-burning power plant activity is increased due to a higher energy consumption of heating systems. Consequently, excessive amounts of aerosol particles and their precursors are emitted (Chameides et al., 1999). Moreover, crop residue burning in the agricultural areas of eastern Asia may enhance aerosol concentrations (Xue et al., 2014). Mineral dust particles, from the Taklamakan and Gobi deserts between middle of spring and end of autumn, are transported through westerly winds (Eck et al., 2005; Proestakis et al., 2017). Collectively, the mix of all these pollutants contributes to the formation of regional brown hazes greatly threatening public health, over the North China Plain during the dry season (from October to March). They have been frequently detected by satellite and groundbased observations (Ma et al., 2010).

Three typical days between October and November 2006 in eastern China were selected to illustrate the performance of the NN algorithm over scenes with strong urban aerosol pollution: day 1 of 2 October 2006, day 2 of 6 October 2006, and day 3 of 1 November 2006. As illustrated by the maps in Fig. 1, these days are characterized by high $\tau$ values over land as shown by Aqua MODIS: $\tau(550 \mathrm{~nm})$ in the range of $0.5-1.6$ in October 2006, and 0.5-1.3 in November 2006. Lin et al. (2015) estimated $\omega_{0}$ values in summer (and likely beginning of autumn) in the range of 0.94-0.96 in the visible. This is likely a consequence of lower black carbon particle amounts at that time (compared to winter and spring) and a high dominance of anthropogenic particles such as nitrate and sulfate. These particles may also be mixed, in parts, with desert dust. Consistently, OMI UVAI depicts for the selected days values lower than or close to 1 (see Fig. 1). Therefore, we use the NN algorithm trained with $\omega_{0}=0.95$ assuming low abundance of UV and visible absorbing particles.

Figure 2 depicts the spatial distribution of retrieved OMI ALH for all the selected collocated OMI-MODIS pixels, with a variability between 0.5 and $3 \mathrm{~km}$. The CALIPSO suborbital tracks were mostly located inland in days 1 and 3 and between inland and over sea in day 2 (see Fig. 1 and Fig. 2). The aerosol layers in the CALIOP L2 product, based on the total backscatter coefficients $(532 \mathrm{~nm})$, are generally located between the surface and $1.5 \mathrm{~km}$ height (see Fig. 3). Maxi- 

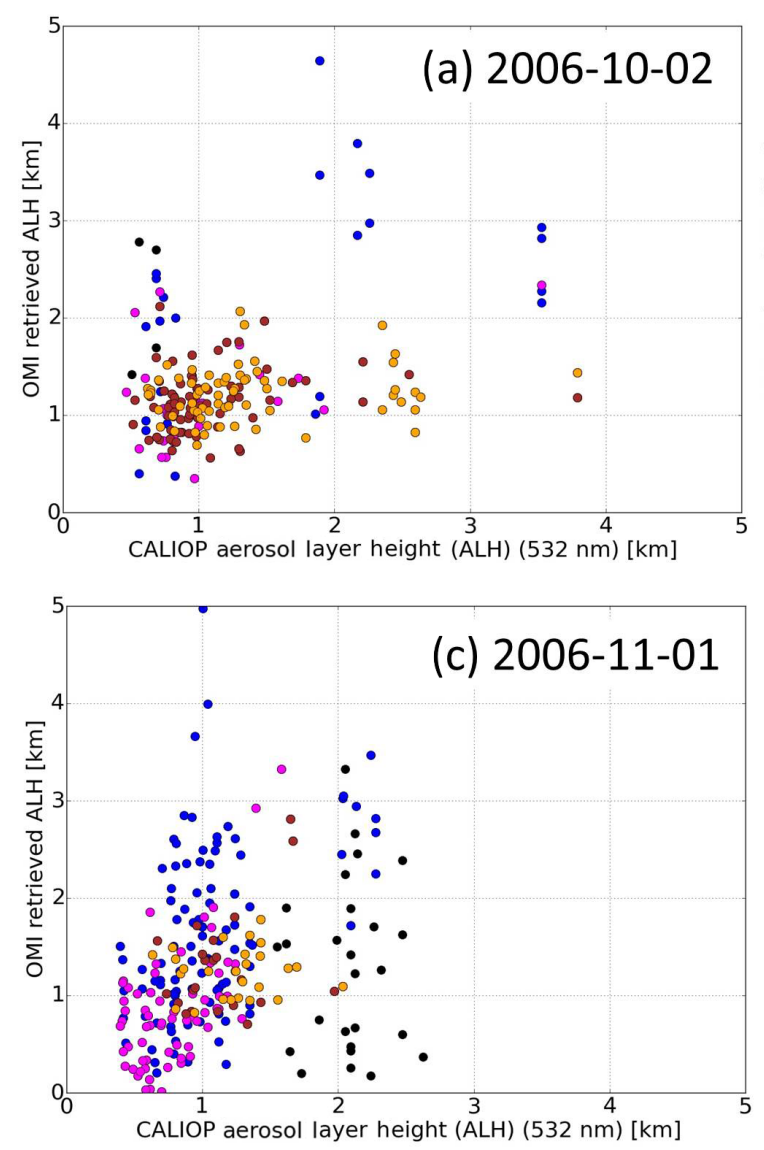

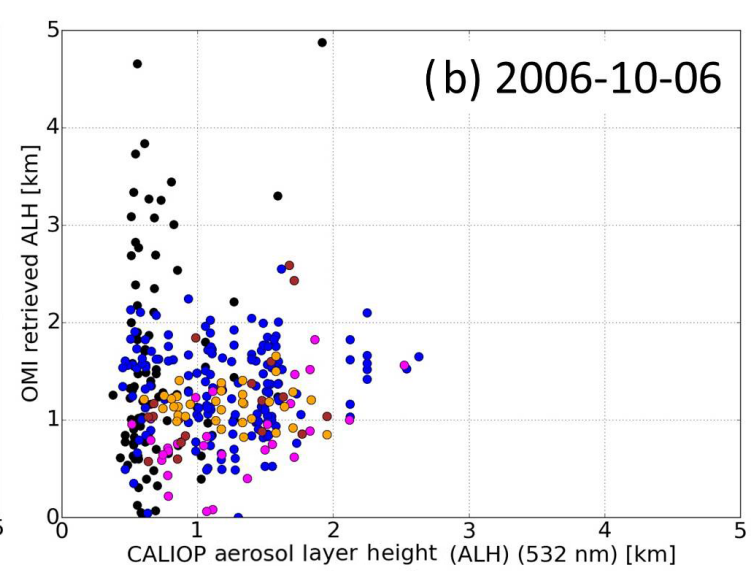

MODIS aerosol optical thickness $\zeta(550 \mathrm{~nm})$ range:

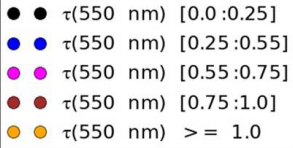

Figure 5. Scatter-plot of collocated retrieved OMI ALH and derived CALIOP ALH (532 nm) (see Sect. 4.1) for urban and industrialized cases over eastern China as a function of MODIS $\tau(550 \mathrm{~nm})$. Distance between OMI and CALIOP pixels is $50 \mathrm{~km}$ : (a) 2 October 2006 , (b) 6 October 2006, and (c) 1 November 2006.

mum top heights do not exceed $2 \mathrm{~km}$ on 6 October 2006 or $3 \mathrm{~km}$ on the 2 other days. Collocated OMI ALH are mostly located in the middle aerosol layers and rarely exceed the top and bottom layer limits (see Fig. 2). Overall, for the 3 selected days, the OMI NN retrievals reproduce the spatial CALIOP L2 patterns. On 2 October 2006 in particular, OMI ALH remains relatively stable at the average altitude of $1 \mathrm{~km}$, within the CALIOP L2 aerosol layers (see Fig. 3a). Only at the latitude $36.5^{\circ} \mathrm{N}$ do both products simultaneously show an increased altitude close to $3 \mathrm{~km}$. On the 2 other selected days, OMI ALH and CALIOP L2 show simultaneously descending slopes from south to north: a slope of about $2 \mathrm{~km}$ over $2.5^{\circ}$ latitude on 6 October 2006 and around $1.5 \mathrm{~km}$ over $8^{\circ}$ latitude on 1 November 2006 (see Fig. 3b and c).

An equivalent CALIOP L2 ALH can be derived by calculating an aerosol extinction weighted average altitude as follows:

$\operatorname{ALH}($ CALIOP L2 $)=\frac{\sum_{1} h(l) \sigma(l)}{\sum_{1} \sigma(l)}$, where $\sigma(l)$ is the CALIOP aerosol extinction $(532 \mathrm{~nm})$ of the vertical layer $l$ defined by its mid-altitude $h(l)$.

In Fig. 4, root-mean-square deviation (RMSD) between OMI and CALIOP L2 ALH lies in the range of 462-648 m when the maximum distance between the selected OMI and CALIOP ground pixels is lower than $50 \mathrm{~km}$ and with collocated MODIS $\tau(550 \mathrm{~nm}) \geq 0.55$ (see Fig. 3). Associated bias values (i.e. average difference between OMI and CALIOP ALH per day) are between -86 and $-128 \mathrm{~m}$. These results significantly deteriorate, firstly when specifying a lower threshold on collocated MODIS $\tau(550 \mathrm{~nm})$ (e.g. RMSD $\geq$ $1000 \mathrm{~m}$ with all MODIS $\tau(550 \mathrm{~nm})$ values included) and secondly with a more flexible distance criterion (e.g. RMSD in the range of 594-888 $\mathrm{m}$ with a maximum distance of $500 \mathrm{~km}$ between the selected OMI and CALIOP ground pixels). The relatively low impact, noticed here, on the distance between OMI and CALIOP pixels is probably related to the large spatial extent of aerosol plumes and their relative spatial homogeneity. The impact of distance between collocated OMICALIOP pixels would be more detrimental over scenes with smaller and/or more heterogeneous plumes. Figure 5 shows the one-to-one comparison between OMI and CALIOP L2 

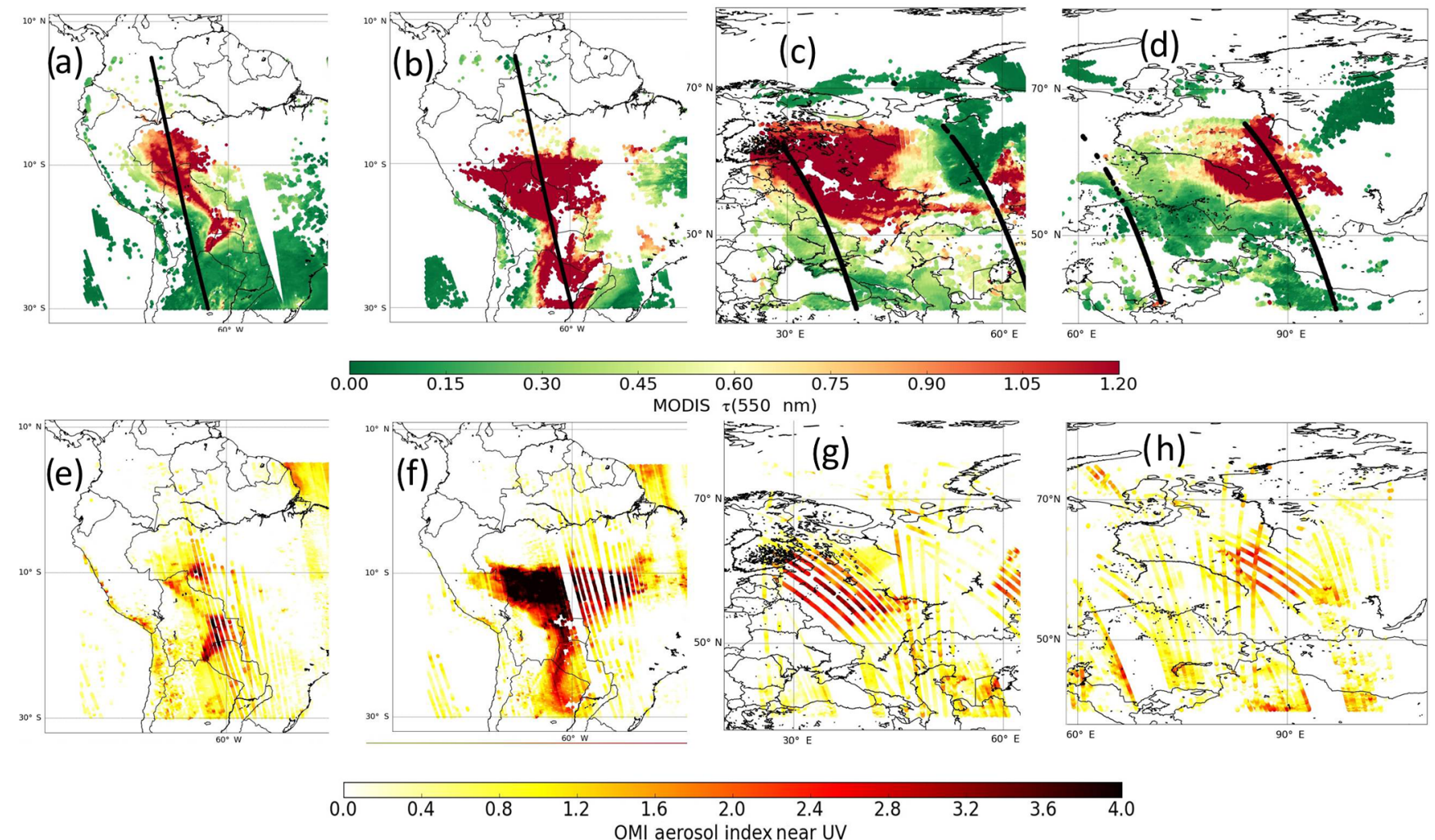

Figure 6. Maps of Aqua MODIS $\tau(550 \mathrm{~nm})$ from the combined DT and DB Collection 6 (see Sect. 2.4) and collocated OMI aerosol index from near-UV (UVAI) values (see Sect. 3) over cloud-free scenes and intensive biomass burning episodes. The dark thick lines represent the track of CALIPSO space-borne sensor over the selected case studies: (a, e) South America on 24 August 2006, (b, f) South America on 30 September 2007, (c, g) eastern Russia on 8 October 2010, and (d, h) eastern Russia on 23 June 2012.

ALH within a distance of $50 \mathrm{~km}$ per case study and as a function of associated MODIS $\tau(550 \mathrm{~nm})$. The correlation coefficient $(R)$ between OMI and CALIOP ALH varies per day, between 0.4 and 0.6 for all scenes with MODIS $\tau(550 \mathrm{~nm}) \geq$ 0.55 .

\subsection{Smoke and absorbing aerosol pollution from biomass-burning}

Intensive biomass burning releases large amounts of carbonaceous and black carbon aerosols. The resulting dense smoke layers have a predominance of fine and strongly lightabsorbing particles, especially in both the UV and visible spectral ranges. Combined with large $\tau$ values, this yields large light extinction and Ångström exponents ( $\geq 1.5$ ) (Torres et al., 2013; Wu et al., 2014). Figure 6 shows the location and associated MODIS $\tau(550 \mathrm{~nm})$ and OMI UVAI values for the selected biomass burning episodes: the two first events are over South America on 24 August 2006 and 30 September 2007; the two last events are over eastern Russia on $8 \mathrm{Au}$ gust 2010 and 23 June 2012. Due to the very high load of absorbing particles with MODIS $\tau(550 \mathrm{~nm} \geq 1.1)$, OMI UVAI values are generally higher than 2 and can locally reach 4 , suggesting the use of the $\mathrm{NN}$ algorithm trained with $\omega_{0}=0.9$ (see Fig. 6).

Several studies have identified loss of sensitivity of CALIOP attenuated backscatter profile measurements at $532 \mathrm{~nm}$ over scenes with dense smoke layers, such as over Canadian boreal and Amazonian fire events (Kacenelenbogen et al., 2011; Torres et al., 2013; Wu et al., 2014). Light extinction due to these layers is much larger at $532 \mathrm{~nm}$ than at $1064 \mathrm{~nm}$ (Pueschel and Livingston, 1990). Since CALIOP does not directly measure the aerosol backscattering but rather the attenuated backscattering, the range-dependent reduction in CALIOP lidar signals due to attenuation occurs more rapidly in the short wavelengths. Therefore, over scenes with heavy smoke particle loads, the attenuated backscatter coefficients $(532 \mathrm{~nm})$ in the lower part of the aerosol layer fall below the CALIOP's detection threshold, preventing the identification of the full vertical extent of the aerosol layers (from the top to the bottom). Being a down-looking observation lidar system, CALIOP tends then to mostly detect the top height compared to the base height of the aerosol layer as the laser's energy undergoes substantial attenuation when the beam travels through an optically thick layer (Vaughan et al., 2005; Kim et al., 2013). Therefore, the identified lay- 

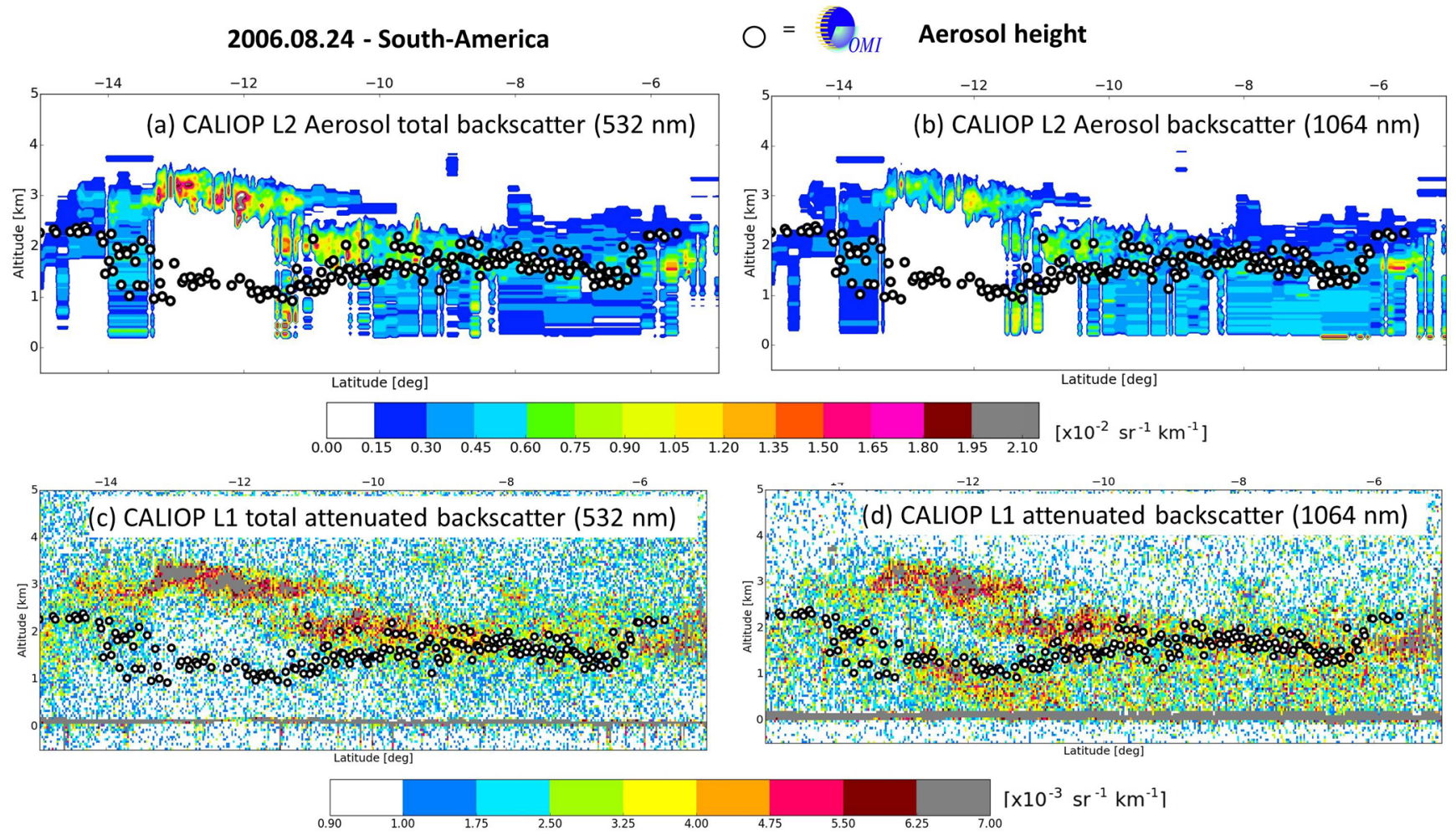

Figure 7. Retrieved OMI ALH compared with CALIOP along-track vertical profile observations for biomass burning case over South America: (a) CALIOP L2 aerosol total backscattering (532 nm), (b) CALIOP L2 aerosol backscattering (1064 nm), (c) CALIOP L1 attenuated backscattering $(532 \mathrm{~nm})$, and (d) CALIOP L1 attenuated backscattering $(1064 \mathrm{~nm})$.

ers that are fully attenuated at $532 \mathrm{~nm}$ in the $\mathrm{L} 1$ product are filtered out in the L2 product. As a consequence of this filtering, CALIOP's $\tau$ of smoke layers is generally underestimated due to an overestimation of the layer base altitude ( $\mathrm{Wu}$ et al., 2014; Kim et al., 2013).

Figure 7 depicts an example of the loss of sensitivity for a biomass burning case in South America. The CALIOP aerosol total backscatter $(532 \mathrm{~nm})$ and backscatter $(1064 \mathrm{~nm})$ coefficients in the L2 product mostly show the top layer of carbonaceous aerosols in the range of $3-4 \mathrm{~km}$ altitude with maximum thickness of $1 \mathrm{~km}$, between 14 and $11^{\circ} \mathrm{S}$ (see Fig. 7a and b). We found that the layers located below are flagged as totally attenuated at the wavelength of $532 \mathrm{~nm}$, according to the CALIOP vertical feature mask. On the northernmost end of the detected plume, the aerosol load is around $2 \mathrm{~km}$ height. In contrast, the CALIOP L1 attenuated backscatter $(1064 \mathrm{~nm})$ profile detects an aerosol layer between the surface and $1.5 \mathrm{~km}$, at the latitudes $11-14^{\circ} \mathrm{S}$. This layer is not observed by the CALIOP L1 total attenuated backscatter $(532 \mathrm{~nm})$ profile (see Fig. $7 \mathrm{c}$ and d) likely due to a better sensitivity of this channel to the particles located close to the surface.

The case of 24 August 2006 over South America shows the retrieved OMI ALH being well located, i.e. below the first elevated aerosol layer (at about $3 \mathrm{~km}$ ) and at the top of the sec- ond aerosol layer, close to the surface (see Fig. 7d). Contrary to the CALIPSO L1 measurement $(532 \mathrm{~nm})$, our retrievals based on OMI visible measurements are not restricted to the top of the smoke or absorbing layer but correctly match with the middle of the layers detected by CALIPSO L1 $(1064 \mathrm{~nm})$. The reason that our OMI ALH seems closer to the top of the second layer may be due to a higher aerosol load and/or different layer properties (see Section 4.2).

Figure 8 shows that similar full CALIOP attenuation processes occur with the other selected biomass burning cases. The CALIOP L1 total attenuated backscatter $(532 \mathrm{~nm})$ vertical profiles mostly correlate with the top of the detected aerosol layers, while the CALIOP L1 attenuated backscatter $(1064 \mathrm{~nm})$ profiles reveal lower layers. On days of 30 September 2007 and 8 August 2010, the top layers are at elevated altitudes (higher than $3 \mathrm{~km}$ ), while the lower ones extend from the surface to $1-2 \mathrm{~km}$. On the last day, 23 June 2012, the top layer is lower (between 1 and $2 \mathrm{~km}$ ). Similarly, all the OMI ALH retrievals are not restricted to the top layers but match, most of the time, with the middle of the layers, sometimes a bit closer to the base of the top layer or the top of the bottom layer. This may depend on the differences in terms of AOD and/or optical properties of each layer (see Sect. 4.2). In addition, it is worth noting the similar vertical variability (around $500 \mathrm{~m}$ ) on 30 September 2007 in 
CALIOP L1 total attenuated backscatter $(532 \mathrm{~nm})$
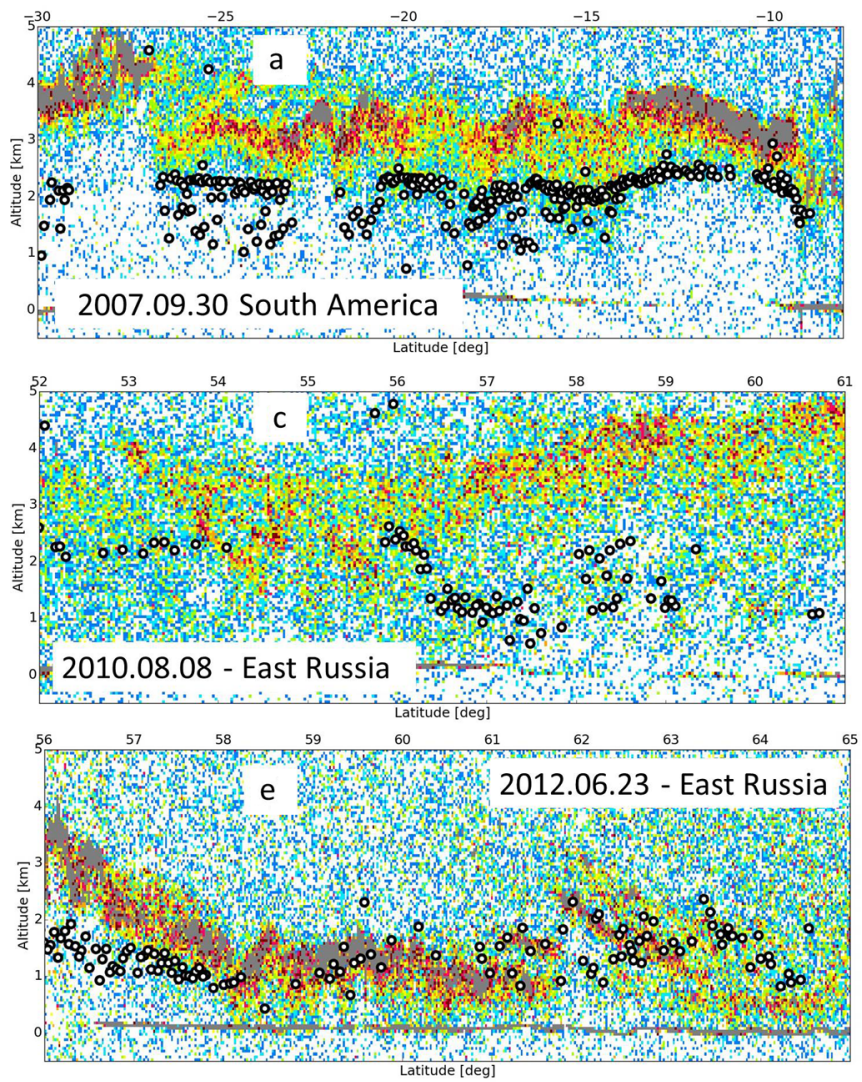

CALIOP L1 attenuated backscatter $(1064 \mathrm{~nm})$
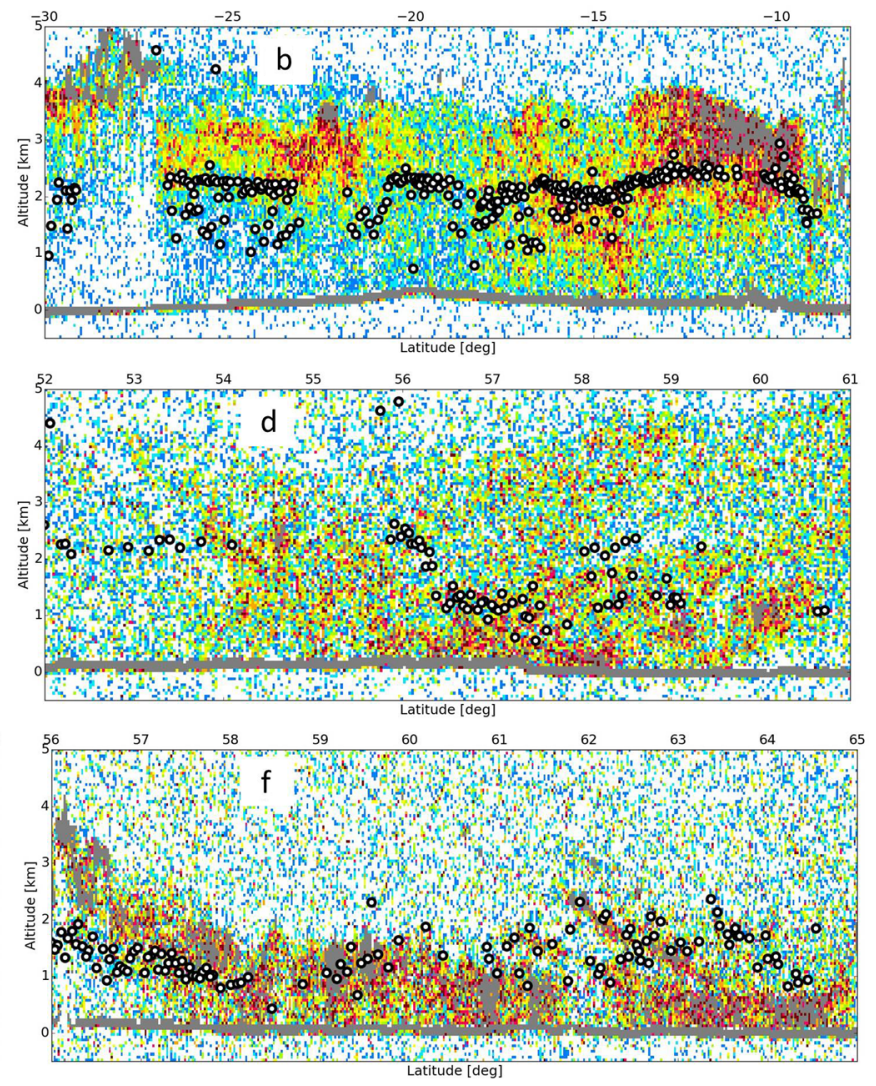

$O=\partial_{O M I}$ Aerosol height

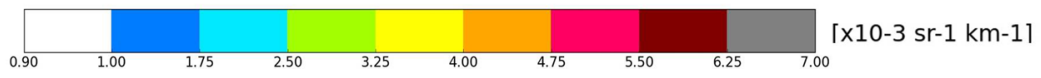

Figure 8. Retrieved OMI ALH compared with CALIOP L1 along-track vertical profile observations (532 and $1064 \mathrm{~nm}$ ) for biomass burning cases: (a, b) 30 September 2007 in South America, (c, d) 8 August 2010 in eastern Russia, and (e, f) 23 June 2012 in eastern Russia.

South America at the latitudes $8-15^{\circ} \mathrm{S}$ and the remarkable descending slope, on 23 June 2012 in eastern Russia, from north to south at the latitudes $56-58^{\circ} \mathrm{S}$ present in both OMI ALH and CALIOP L1 products.

Three reasons may explain why OMI visible spectra allow us to probe an entire absorbing aerosol layer, contrary to the active satellite visible measurement of CALIOP: (1) OMI measurements rely on the sun irradiance, which is much more intense than the laser pulse of CALIOP; (2) OMI measurements are largely issued from multiple scattering effects occurring at different altitudes, allowing a higher number of photons to reach the lower atmospheric layers; (3) the relatively higher signal-to-noise ratio (SNR) of OMI likely allows us to better detect and exploit the upcoming signal from smoke layers. In contrast, contributions of multiple scattering to the CALIOP backscattered signals are lower than single scattering effects within moderately dense dust layer and insignificant within smoke aerosol extinction (Winker, 2003; Liu et al., 2011). Furthermore, retrieving vertical profile of smoke layers from CALIOP requires a high aerosol extinc- tion threshold due to the large associated lidar ratio and thus low SNR (Winker et al., 2013).

\subsection{Desert dust transport}

The case illustrated in Fig. 9a is a large desert dust plume over ocean surface, with MODIS $\tau(550 \mathrm{~nm})$ values up to 1.1 , released from the Sahara and transported through westerly winds along the African coast. It occurred in summer on 19 July 2007. Since the Sahara is the most important source of mineral particles, associated dust aerosols include hematite and other iron oxides. Spectrally, desert dust is a UV-absorbing particle but quite highly scattering in the visible (contrary to smoke) and longer wavelengths, leading to the appearance of relatively bright plumes (light brown) over the dark marine surface from a satellite point of view. The NN algorithm trained with aerosol $\omega_{0}=0.95$ is therefore used here.

The vertical profile of CALIOP L2 aerosol total backscatter $(532 \mathrm{~nm})$ shows elevated layers, ranging from $1-2 \mathrm{~km}$ at $15^{\circ} \mathrm{S}$ to $3-6 \mathrm{~km}$ at $23^{\circ} \mathrm{S}$ (see Fig. $9 \mathrm{~b}$ ). Such a slope likely 

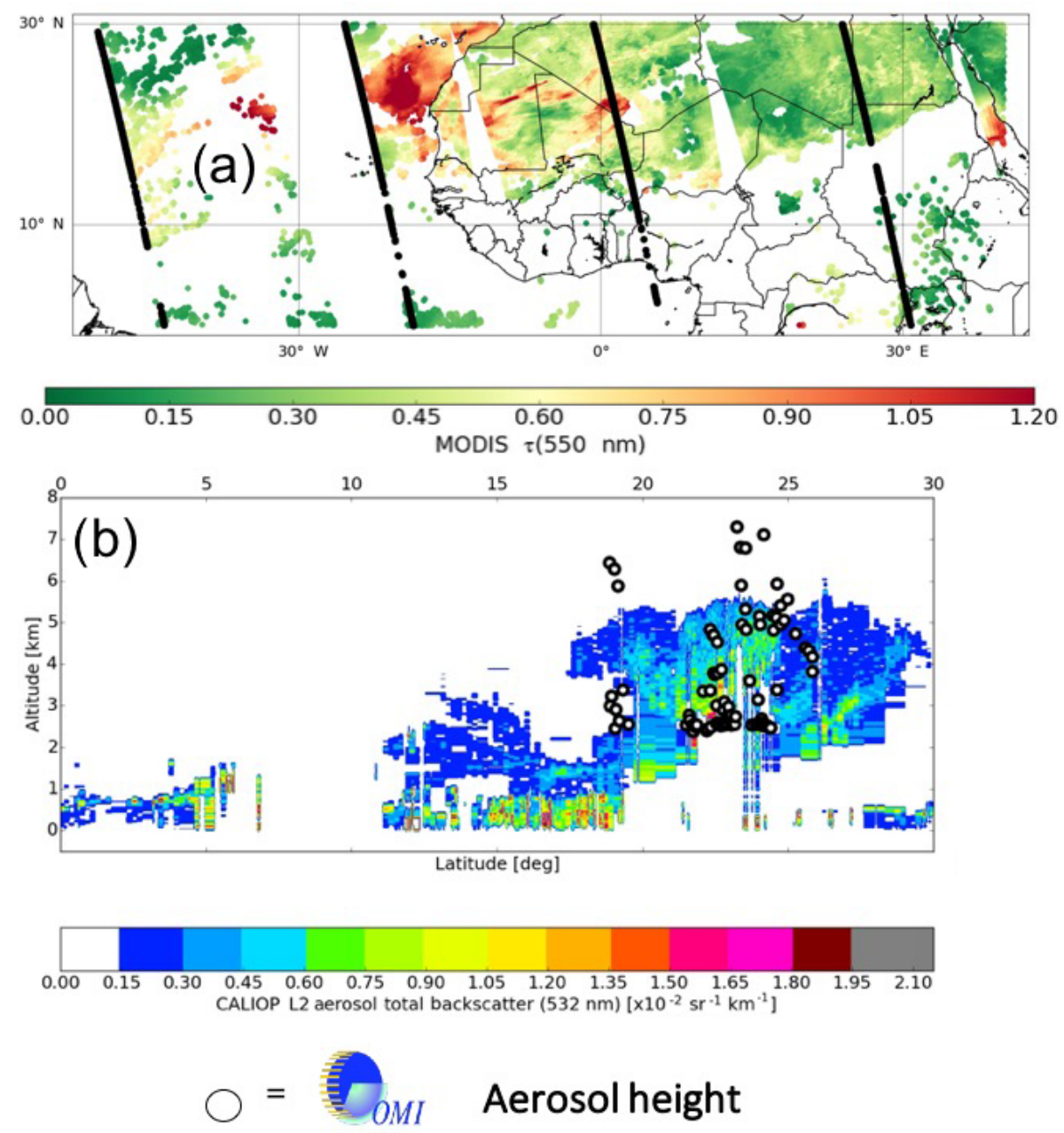

Figure 9. Elevated layer due to a Saharan dust outbreak transported to western Mediterranean region over sea on 19 July 2007. (a) Map of Aqua MODIS $\tau(550 \mathrm{~nm}$ ) from the combined DT and DB Collection 6 (see Sect. 2.3). (b) Retrieved OMI ALH compared with vertical profile of aerosol total backscatter coefficient $(532 \mathrm{~nm})$ from the CALIOP L2 aerosol total backscatter $(532 \mathrm{~nm})$ associated with the second left CALIPSO track over sea in Fig. 9a.

results from large-scale circulation governed by subtropical subsidence of the Intertropical Convergence Zone's northern branch, dry air from the desert, and the Saharan intense sensible heating effect perturbing the temperature inversion layers and thus creating convection uplifting dust from the surface (Prospero and Carlson, 1981). Generally, the OMI ALH results are consistent with CALIOP observations, with elevated values lying between 2 and $7 \mathrm{~km}$. They are mostly located in the middle of the large uplifted dust plume from south to north. The average difference between OMI and CALIOP L2 ALH, collocated within a distance of $100 \mathrm{~km}$, is $-350 \mathrm{~m}$. However, OMI ALH depicts significant variabilities compared to CALIOP ALH. The SD of the related differences is therefore quite large, about $2.1 \mathrm{~km}$.

Several elements likely contribute to the difficulties encountered in this case study. Desert dust particles can be relatively coarse (thus low $\alpha$ value) and are irregularly shaped (i.e. non-spherical). Their optical modelling in the NN training dataset regarding their assumed size and the employed phase function model (see Sect. 2.2) may contribute to the higher ALH uncertainties than in urban cases of Sect. 3.2 (see further discussions in Sect. 4.3 and 4.4).

\section{Specific error analysis}

The analysed OMI ALH in Sect. 3 may include uncertainties due to assumptions made on the aerosol models used in the NN training dataset. The following subsections focus on some specific uncertainty sources that are relevant for these specific case studies. They provide further detailed error analysis and are complementary to the evaluations performed in (Chimot et al., 2017). Most of these analyses are based on synthetic scenarios. Simulations are performed in a similar way as in the NN training dataset (see Sect. 2.2). 


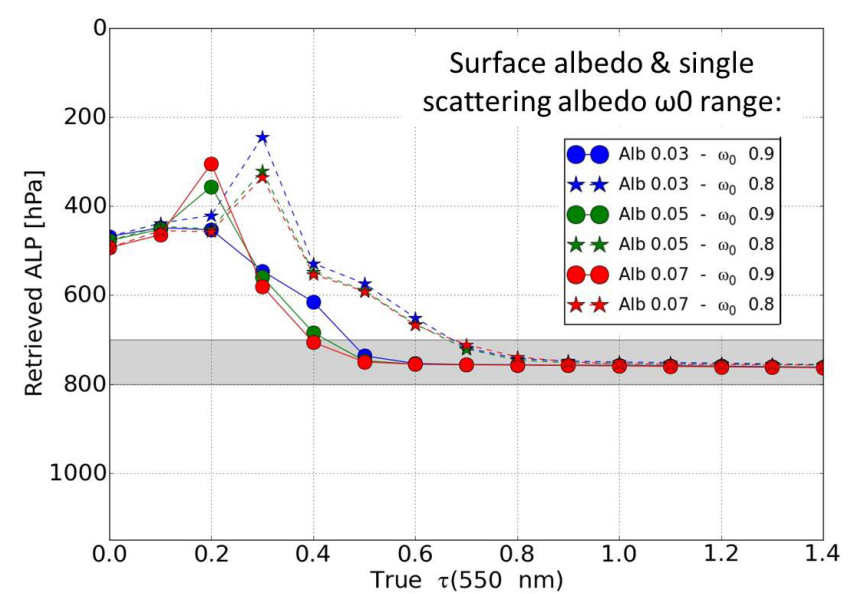

Figure 10. Simulated ALP retrievals, based on noise-free synthetic spectra with aerosols, as a function of true $\tau(550 \mathrm{~nm})$. All the retrievals are achieved with the $\mathrm{NN}$ algorithm trained with aerosol $\omega_{0}=0.9$ and true prior $\tau(550 \mathrm{~nm})$ value. The assumed geophysical conditions are temperature, $\mathrm{H}_{2} \mathrm{O}, \mathrm{O}_{3}$, and $\mathrm{NO}_{2}$ from climatology mid-latitude summer, $\theta_{0}=25^{\circ}, \theta=45^{\circ}$, and $P_{\mathrm{S}}=1010 \mathrm{hPa}$. The reference aerosol scenario assumes fine scattering particles $(\alpha=1.5, g=0.7)$ and two aerosol $\omega_{0}$ values: 0.9 and 0.8 . Its location is depicted by the grey box, between 700 and $800 \mathrm{hPa}$.

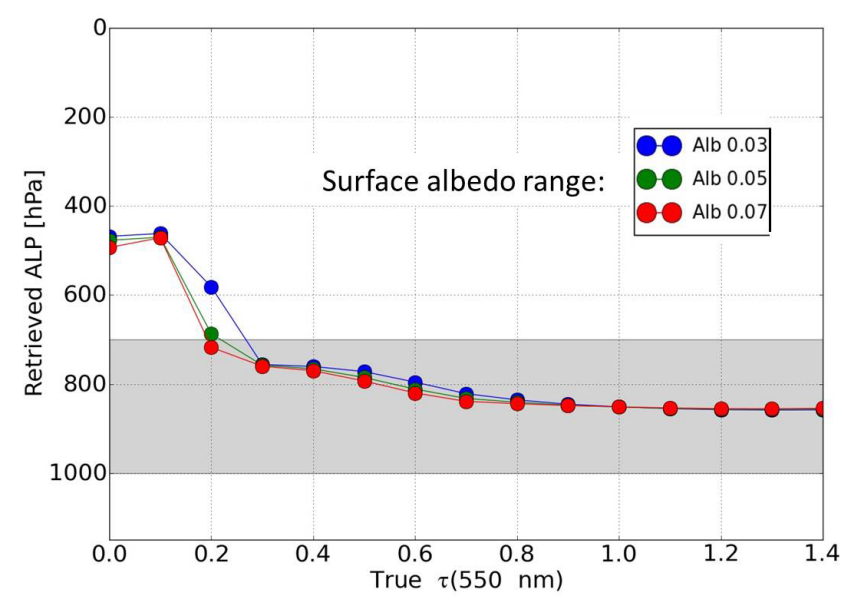

Figure 11. Same as Fig. 10 but with one unique aerosol $\omega_{0}$ value (= 0.9 ) and a larger geometric extension of the aerosol layer included in the simulated spectra, i.e. between 700 and $1000 \mathrm{hPa}$.

No bias is introduced in the geophysical parameters such as surface, temperature profile, and atmospheric trace gases. The true prior aerosol $\tau(550 \mathrm{~nm})$ value is given for all the retrievals. Aerosols are assumed to cover the full ground pixel. The key analysed variable is the aerosol layer pressure (ALP), which corresponds to ALH expressed in hPa in order to be consistent with all the input parameter specifications (e.g. vertical grid) in the radiative transfer simulations.

\subsection{Aerosol single scattering albedo}

Aerosol $\omega_{0}$ represents the scattering vs. absorption efficiency of the particles and therefore directly drives the magnitude of the applied shielding effect on the $\mathrm{O}_{2}-\mathrm{O}_{2}$ dimers (Chimot et al., 2016). An overestimated $\omega_{0}$, in the training database, directly leads to an overestimation of ALH (or underestimation of ALP) as the measured $N_{\mathrm{O}_{2}-\mathrm{O}_{2}}^{\mathrm{s}}$ is lower (i.e. stronger shielding) than expected if one knows the true extinction profile and assumes a biased $\omega_{0}$ (Chimot et al., 2017).

Dense smoke layers from wildfires, such as those analysed in Sect. 3.2, may contain particles that are more absorbing than the assumed aerosol model. Figure 10 illustrates the impact of particles with $\omega_{0}=0.8$ while the $\mathrm{NN}$ algorithm trained with $\omega_{0}=0.9$ is used (same as in Sect. 3.2). No errors are introduced in all the other geophysical parameters. The resulting ALP values are overestimated with a bias up to $100 \mathrm{hPa}$ (around $900 \mathrm{~m}$ ) for scenes with $\tau(550 \mathrm{~nm})$ in the range of 0.5-0.9. ALP biases are almost null over scenes with higher aerosol load as the shielding effect due to the already high amount of particles clearly dominates over their optical properties. In these conditions, the shielding effect induced by particles is less dependent on $\omega_{0}$ assumptions. These results are in line with those estimated from the use of the NN algorithm trained with $\omega_{0}=0.95$ in Chimot et al. (2017).

\subsection{Aerosol vertical distribution}

Due to the specific limitations of passive satellite sensor, the OMI ALH retrieval summarizes the description of the aerosol extinction profile in a single scalar value, assuming a specific profile shape. However, aerosol profiles in the observed scene may considerably deviate from this simplified profile description. It is then legitimate to ask the meaning of the retrieved ALH. As explained in Sect. 2, the NNs were trained based on a single "box layer" with a constant geometric thickness of about $1 \mathrm{~km}$ (100 hPa exactly), ALP (ALH) being then the mid-pressure (mid-altitude) of this layer. Several of the analysed cases in Sect. 3 depict more extended aerosol layers (e.g. up to $3.5 \mathrm{~km}$ in Fig. 8b) or two separate layers (e.g. Fig. 7b).

Figure 11 illustrates the retrievals in a case of an extended aerosol layer with thickness of $300 \mathrm{hPa}$, located between 700 and $1000 \mathrm{hPa}$. The derived ALP values are close to $850 \mathrm{hPa}$ for scenes with $\tau(550 \mathrm{~nm}) \geq 0.5$, which thus corresponds to the mid-level of the simulated layer. This result may be understood as the true aerosol vertical extinction profile being lower than the assumption. The retrieval then reaches the average altitude where most of the $\mathrm{O}_{2}-\mathrm{O}_{2}$ is actually shielded.

In Fig. 12, ALP is retrieved when two separate aerosol layers with same thickness (i.e. $100 \mathrm{hPa}$ ) are simulated: an elevated one between 600 and $700 \mathrm{hPa}$ and a lower one between 900 and $1000 \mathrm{hPa}$. Assuming that both layers have same optical properties, ALP is retrieved close to $800 \mathrm{hPa}$ for $\tau(550 \mathrm{~nm}) \geq 0.5$ (see Fig. 12a). Here, the retrieval corre- 

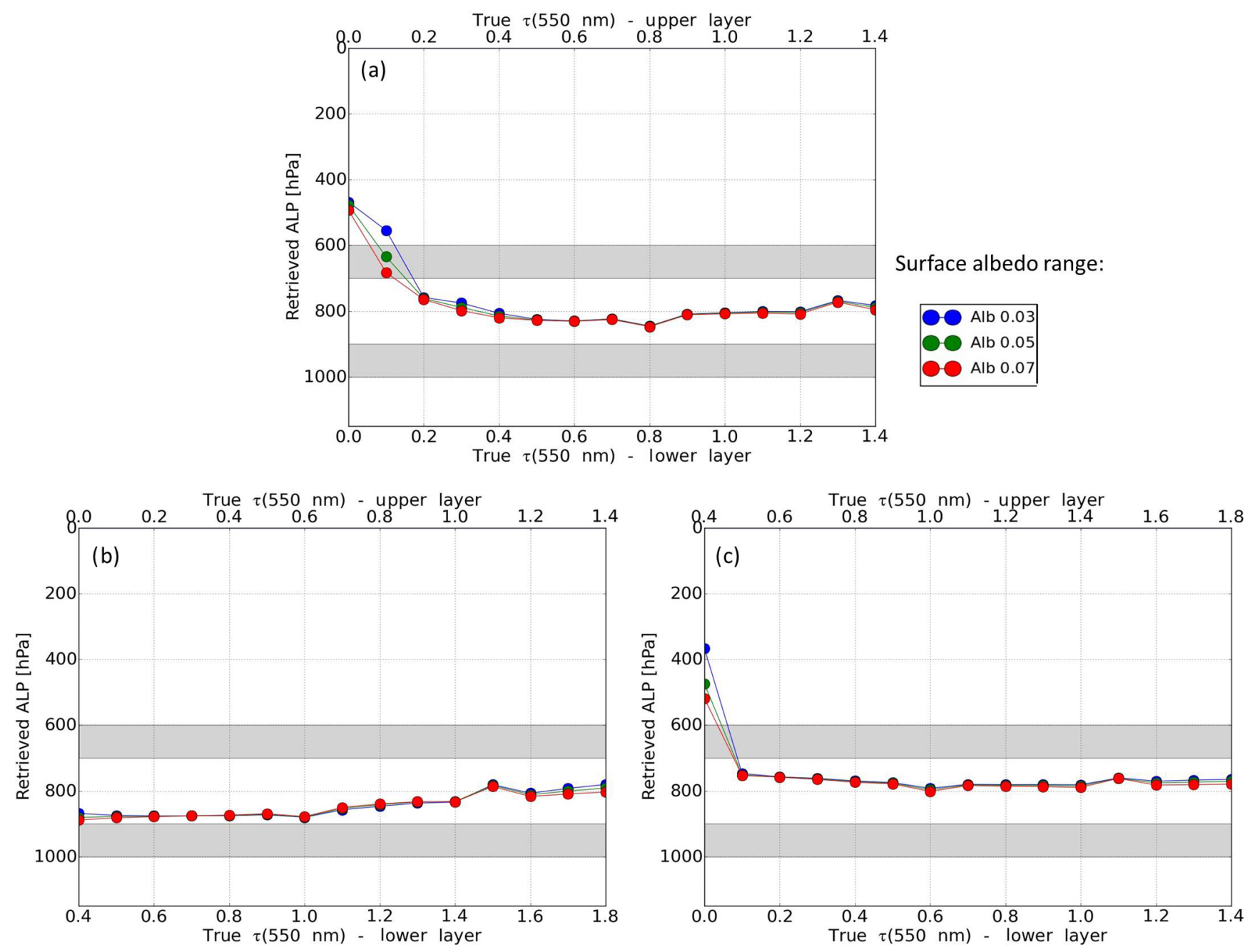

Figure 12. Same as Fig. 10 but with one unique aerosol $\omega_{0}$ value $(=0.9)$ and two separate aerosol layers included in the simulated spectra. The bottom $x$ axis corresponds to the $\tau(550 \mathrm{~nm})$ value of the lower layer, while the top $x$ axis is the $\tau(550 \mathrm{~nm})$ value of the upper layer. Both layers have same geometric thickness (i.e. $100 \mathrm{hPa}$ ). The first is located between 600 and $700 \mathrm{hPa}$, and the second is between 900 and $1000 \mathrm{hPa}$. (a) Both aerosol layers have same optical properties and $\tau(550 \mathrm{~nm})$ values. (b) Both aerosol layers have same optical properties but different $\tau(550 \mathrm{~nm})$ values: the lower layer has systematically a higher $\tau(550 \mathrm{~nm})$ (i.e. +0.4 for each scenario). (c) Both aerosol layers have same optical properties but different $\tau(550 \mathrm{~nm})$ values: the upper layer has systematically a higher $\tau(550 \mathrm{~nm})(\mathrm{i} . \mathrm{e}$. $+0.4 \mathrm{for}$ each scenario).

sponds to the average height of both layers. However, when one of these layers has a higher aerosol load (i.e. a higher value for $\tau(550 \mathrm{~nm}))$, the retrieval is close to the optically thicker aerosol layer for total $\tau(550 \mathrm{~nm})$ in the range of $0.0-$ 1.6 and reaches the average height (i.e. $850 \mathrm{hPa}$ ) for total $\tau(550 \mathrm{~nm}) \geq 1.6$. This demonstrates the sensitivity of the retrieval to the extinction properties of the particles and its vertical distribution driving the location where most of the $\mathrm{O}_{2}-\mathrm{O}_{2}$ dimers are shielded. As a consequence, the retrieved ALP and ALH actually represent a weighted average of the actual aerosol vertical distribution, the weights being the extinction values distributed along the vertical atmospheric layers.

\subsection{Aerosol size}

Within the HG phase function model, particle size is primarily governed by $\alpha$, which describes the spectral variation of the aerosol load $\tau$. While the NNs were trained for fine particles emitted from anthropogenic activities such as power plants and vehicles (i.e. $\alpha=1.5$ ), other particles such as dust can be coarser.

Figure 13 depicts the ALP retrievals assuming scattering particles with $\omega_{0}=0.95$ (same as in Sect. 3.4) but with different $\alpha$ values: 1.5 (consistent with the training dataset) and 0.5. Overestimating $\alpha$ (i.e. underestimating particle size) leads to a increase (decrease) of retrieved ALP (ALH). This is because coarser particles generally extend the length of the average light path, due to reduced multiple scattering, 


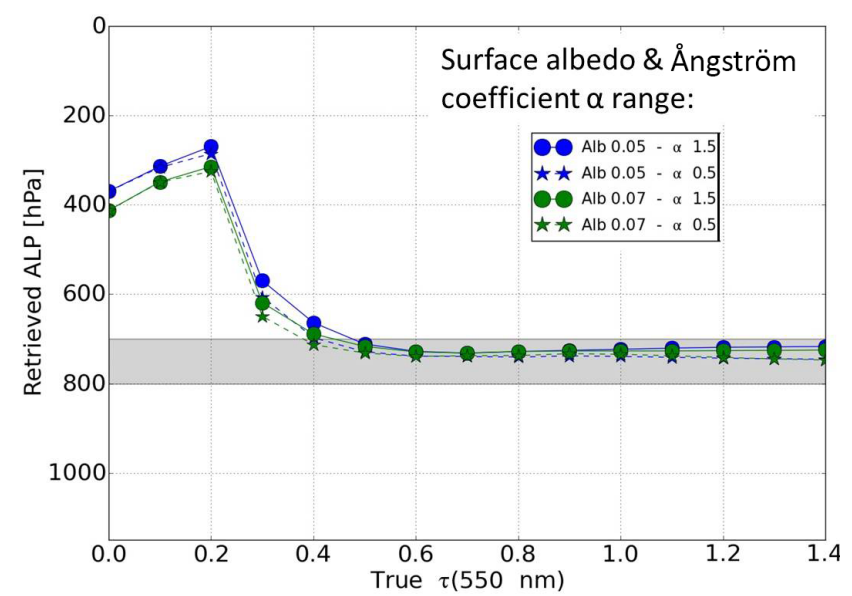

Figure 13. Same as Fig. 10 but with one unique aerosol $\omega_{0}$ value $(=0.95)$ and two aerosol $\alpha(1.5$ and 0.5$)$ in the reference aerosol scenarios. ALP retrievals are estimated from the NN algorithm trained with aerosol $\omega_{0}=0.95$ similarly to the desert dust case in Sect. 3.4.

lower the $\mathrm{O}_{2}-\mathrm{O}_{2}$ shielding, and thus increase the measured $N_{\mathrm{O}_{2}-\mathrm{O}_{2}}^{\mathrm{s}}$ as shown in Chimot et al. (2016). The ALP change is nevertheless about $25 \mathrm{hPa}$.

\subsection{Scattering phase function}

Modelling the aerosol scattering phase function requires precise information not only on their size and optical properties but also on their shape and the phase function modelling theory itself. As an example, optical modelling of desert dust can, for some applications, be done using Mie theory, which is mostly valid for homogeneous and spherical particles, whereas for other applications one could better consider alternative spheroids or T-matrix/geometric optics traditionally used for non-spherical particles (de Graaf et al., 2007; $\mathrm{Xu}$ et al., 2017).

For reasons explained in Sect. 2.2, the HG was employed in the NN training database. This may lead to some errors in ALH and ALP retrievals due to inaccurate scattering angular dependence, depending on the particle type and the assumed $g$ parameter. The shape of the phase function is parameterized by $g$ in HG modelling, which reproduces well the Mie scattering function and thus spherical particles. In Chimot et al. (2016), we demonstrated that bias on ALP does not exceed $50 \mathrm{hPa}$ for a typical uncertainty of 0.1 on $g$ over scenes with $\tau(550 \mathrm{~nm}) \geq 0.5$, assuming no additional bias on $\alpha$ or $\omega_{0}$. Comparison between Mie and HG modelling would mix errors caused by these three parameters altogether, which would then make complex to identify the actual error source. Colosimo et al. (2016) and Sanders et al. (2015) show with simulation studies comparing phase function models, although in different spectral bands, that using a scattering layer with constant particle extinction coefficient does reasonably well without additional biases than those analysed in the previous sections.

Pure desert dust particles are known to be irregularly shaped, and thus the use of the HG forward model may be inappropriate in Sect.3.3 and Fig. 9. Furthermore, by using a prior $\tau$ parameter from MODIS, that may also be derived from an inaccurate and different model, can add some inconsistencies in the OMI ALH retrieval. This may explain in part the larger uncertainties found in Sect.3.3. In further steps, to confirm the real performances of ALH retrievals over a long time series of OMI measurements and/or a potential implementation in the OMI processing chain, new NN algorithms should be designed and trained with a larger dataset that includes accurate aerosol parameters (size and $\omega_{0}$ ) combined with different detailed models of the phase function. Each of these algorithms should be evaluated on a high number of specific observations to conclude on the exact aerosol model type to be assumed for the OMI visible spectral measurements.

\subsection{Cloud contamination}

When backscattered solar light measurements from UV-vis passive satellite sensors are exploited, detecting cloud-free pixels is one of the most crucial prerequisite for aerosol retrievals. In spite of a strict cloud filtering applied in Sect. 3.1, some small cloud residuals may remain in the analysed scenes, especially over biomass burning episodes where the distinction of dense smoke particles and small cloud layers can be difficult.

Presence of cloud layers have similar effects as aerosols on the OMI visible measurements and the $\mathrm{O}_{2}-\mathrm{O}_{2}$ molecules, although associated optical thickness are an order of magnitude higher. In Fig. 14, cloud layers were added to an aerosol layer located between 700 and $800 \mathrm{hPa}$. Clouds were simulated as an opaque Lambertian bright layer with an albedo of 0.8 and different effective cloud pressure and fraction values. Such a model is similar to what is employed in the OMCLDO2 algorithm to detect and characterize the presence of clouds within the OMI pixel or to implicitly correct aerosol effect in trace gas retrievals (Acarreta et al., 2004; Veefkind et al., 2016; Boersma et al., 2011; Chimot et al., 2016). It should be noted that aerosols are assumed to cover the whole scene in the simulations.

Figure 14 shows that the impact on the ALP retrieval strongly depends on the cloud altitude. If the aerosol layer is located below a cloud with an effective fraction of 0.3 , the ALP is strongly biased low (i.e. ALH high) for $\tau(550 \mathrm{~nm}) \leq$ 0.8 , while it tends towards the effective cloud pressure for $\tau(550 \mathrm{~nm}) \geq 0.8$ (see Fig. 14c). Such a behavior may be explained by the high $\mathrm{O}_{2}-\mathrm{O}_{2}$ shielding caused by the clouds, much higher than what is anticipated by the retrieval algorithm through the given aerosol $\tau(550 \mathrm{~nm})$. The assumed optical thickness of the scene is too low to match with the strongly reduced $N_{\mathrm{O}_{2}-\mathrm{O}_{2}}^{\mathrm{s}}$ measurement, especially over 

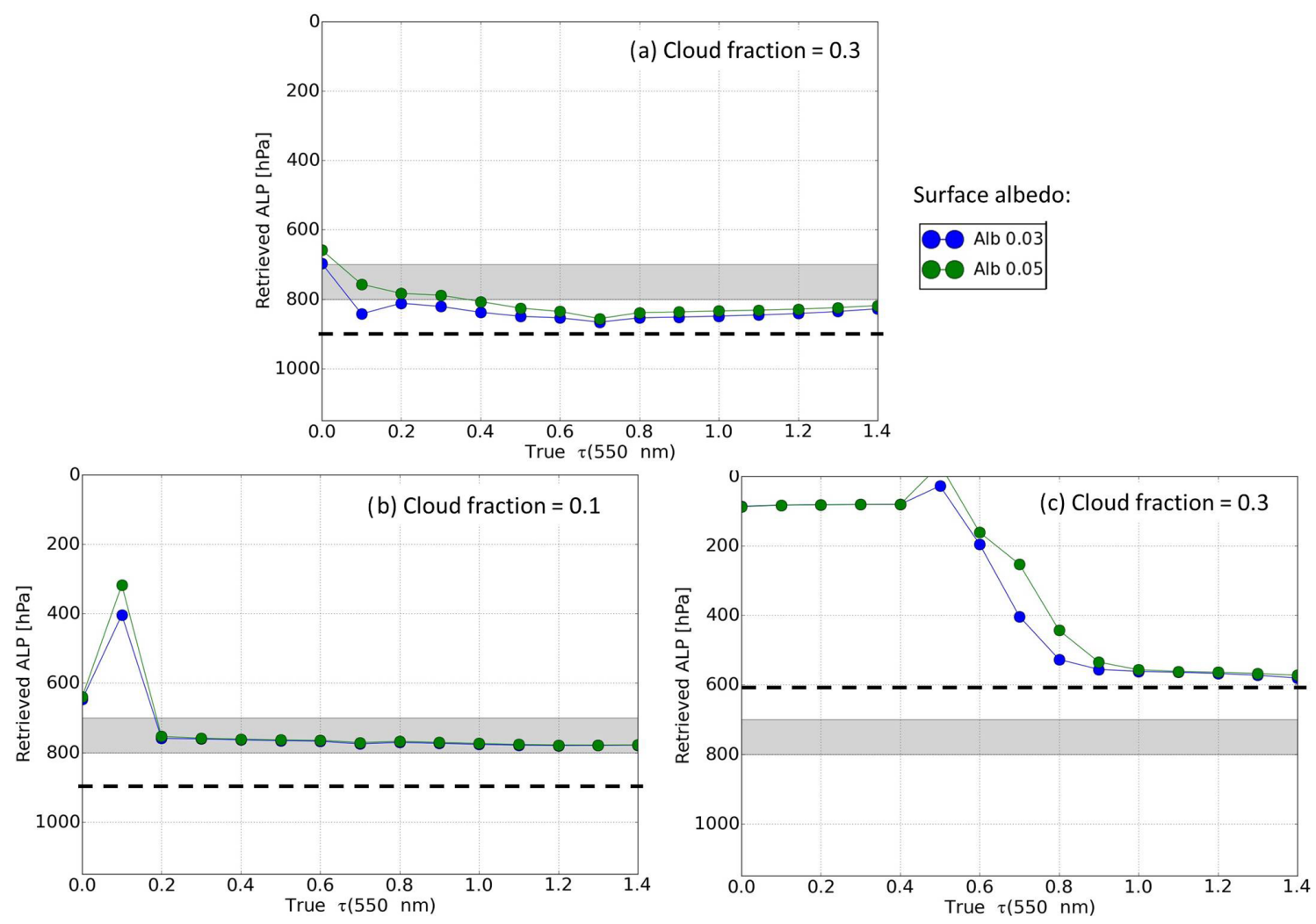

Figure 14. Same as Fig. 10 but with one unique aerosol $\omega_{0}$ value (0.9) and the inclusion of a cloud (dashed thick black line) in addition to the aerosol layer. The cloud reflectance is simulated via a simple opaque (cloud albedo of 0.8) and Lambertian layer. (a) Effective cloud fraction of 0.3 and cloud pressure of $900 \mathrm{hPa}$. (b) Effective cloud fraction of 0.1 and cloud pressure of $900 \mathrm{hPa}$. (c) Effective cloud fraction of 0.3 and cloud pressure of $600 \mathrm{hPa}$.

scenes with a small aerosol load. Moreover, the opaque and bright cloud shields part of the scattering layer located below and dominates over the aerosol signal. The retrieval compensates then with a strongly reduced ALP value. When a high aerosol load (both in the scene and in the prior information) roughly corresponds to the optical thickness of the scene, the ALP represents the altitude where most of the $\mathrm{O}_{2}-\mathrm{O}_{2}$ shielding occurs: at the cloud level. This last effect is also visualized in Sanders et al. (2015) with an optically thick aerosol layer and a cirrus above it, although a different spectral band in the near-infrared is employed.

In contrast, if aerosols are located above the cloud with an effective fraction of 0.3 , retrieved ALP is located between both layers (see Fig. 14a). Part of the cloud signal is attenuated this time. Similarly to Sect. 4.2, ALP likely represents a weighted average of the extinction vertical profile. This average is weighted not only by the aerosol properties and the cloud altitude but also by the effective cloud fraction. In the presence of a reduced effective cloud fraction ( 0.1 instead of 0.3 ), the estimated ALP is lower (decrease of $40 \mathrm{hPa}$ ), close to the base height of the aerosol layer.

\section{Conclusions}

Following the study of Chimot et al. (2017), aerosol layer heights (ALHs) were retrieved from OMI cloud-free pixels using the $\mathrm{O}_{2}-\mathrm{O}_{2}$ visible absorption band at $477 \mathrm{~nm}$, based on a neural network approach. The physical principle relies on the dependency of the shielding of the $\mathrm{O}_{2}-\mathrm{O}_{2}$ dimers on the aerosol height. Three days with urban and industrial pollution episodes in eastern China, 4 days with widespread biomass burning events in South America and Russia, and 1 day of a Saharan dust plume transport event over ocean were studied in detail. The goal was to evaluate the OMI ALH spatial patterns over case studies. Prior aerosol optical thickness $\tau(550 \mathrm{~nm})$ information was used from collocated MODIS L2 products (Dark Target and Deep Blue algorithms). The retrievals were compared with CALIOP along-track product. The selection of events largely depends on the availability of coinciding OMI and CALIOP data over relevant cases.

Good agreement was found between OMI and CALIOP ALH, where the latter was derived from the L2 aerosol extinction profile, over urban and industrial pollution episodes: we find RMSD in the range of $462-648 \mathrm{~m}$ for distances between OMI and CALIOP ground pixels smaller than 
$50 \mathrm{~km}$ and with collocated MODIS $\tau(550 \mathrm{~nm}) \geq 0.55$. Similar spatial patterns are also observed between both sensors. Carbonaceous and black carbon particles within dense smoke layers over biomass burning events strongly attenuate the CALIOP backscatter signal $(532 \mathrm{~nm})$. As attenuated backscatter profiles decrease more rapidly in the short than in the long wavelengths, only CALIOP L1 measurements $(1064 \mathrm{~nm})$ allow us to probe the entire vertical extent of smoke aerosol layers. OMI ALH retrievals match well with these last CALIOP measurements. The higher sensitivity of visible spectral measurements acquired by passive satellite sensors, such as OMI, to capture information from lower altitudes of an optically thick absorbing layer is probably due to the observation of multiple scattered lights from different atmospheric altitudes combined with a higher signal-to-noise ratio than CALIOP. While scattering leads to a strong reduction of the active signal (i.e. lidar) in penetration depth, this reduction is much lower for a remote sensing sensor using the solar light source because the fraction of detected photons that reached the lower part of the aerosol layer is considerably higher. Finally, although OMI ALH shows in general consistent results with respect to CALIOP over the transport of the Saharan dust plume over ocean (difference median of $-557.8 \mathrm{~km}$ ), it remains locally limited likely due to the potential artefacts due to inaccurate modelling of this particle type in the NN training database, notably regarding its nonspherical and irregular shape and coarse size.

Detailed analyses and discussions on specific error sources confirm that prior assumptions on aerosol optical properties are the key crucial factor affecting the OMI ALH retrieval accuracy over cloud-free scenes. In particular, the combination of aerosol single scattering albedo, particle size and shape, and the angular dependency of the scattering phase function assumptions may impact up to $500 \mathrm{~m}$ for each individual parameter. The reason is the direct impact of these variables on the $\mathrm{O}_{2}-\mathrm{O}_{2}$ dimers shielding applied by aerosols. Furthermore, a strict cloud filtering is required to distinguish aerosol from cloud effects. The impact of cloud residuals is a function of the cloud coverage and vertical location with respect to the aerosol layer. Finally, the true meaning of the retrieved ALH parameter depends on the actual aerosol vertical distribution. It can be summarized as the weighted average of the optical (or extinction) particle properties along the vertical atmospheric layers, an optically thick (or strongly absorbing) layer having more weights than an optically thin (or highly scattering) particle layer.

Future works should include further comparisons with multiple sensors (satellite, ground-based, and airborne), generation of yearly series, trend analysis, and evaluation of aerosol effect correction in support of satellite UV-vis trace gas retrievals (e.g. tropospheric $\mathrm{NO}_{2}$ ). The use of satellite $\mathrm{O}_{2}-\mathrm{O}_{2}$ visible absorption band should be further studied for aerosol retrievals in addition to the consideration of the more traditional $\mathrm{O}_{2}$ band in the near-infrared as it may bring additional relevant information. Moreover, expectation for air quality and climate research from a future global OMI ALH product, with a high temporal resolution, should be further investigated, and required improvements should be implemented for an optimal exploitation.

Data availability. All the data results and specific algorithms created in this study are available from the authors upon request. If you are interested in obtaining access to them, please send a message to julien.chimot@eumetsat.int and pepijn.veefkind@knmi.nl. The pybrain library code is available at http://www.pybrain.org/pages/ download (Schaul et al., 2010). Finally, The OMCLDO2 dataset is available from the NASA archives: https://disc.gsfc.nasa.gov/uui/ datasets/OMCLDO2_003/summary (NASA, 2017).

Competing interests. The authors declare that they have no conflict of interest.

Acknowledgements. This work was funded by the Netherlands Space Office (NSO) under the OMI contract. The authors thank Piet Stammes from KNMI for the discussions about aerosol modelling and measurements and Marc Vaughan from NASA for CALIOP aerosol discussions.

Edited by: Omar Torres

Reviewed by: two anonymous referees

\section{References}

Acarreta, J. R., de Haan, J. F., and Stammes, P.: Cloud pressure retrieval using the $\mathrm{O}_{2}-\mathrm{O}_{2}$ absorption band at $477 \mathrm{~nm}, \quad$ J. Geophys. Res.-Atmos., 109, D05204, https://doi.org/10.1029/2003JD003915, 2004.

Amiridis, V., Marinou, E., Tsekeri, A., Wandinger, U., Schwarz, A., Giannakaki, E., Mamouri, R., Kokkalis, P., Binietoglou, I., Solomos, S., Herekakis, T., Kazadzis, S., Gerasopoulos, E., Proestakis, E., Kottas, M., Balis, D., Papayannis, A., Kontoes, C., Kourtidis, K., Papagiannopoulos, N., Mona, L., Pappalardo, G., Le Rille, O., and Ansmann, A.: LIVAS: a 3-D multi-wavelength aerosol/cloud database based on CALIPSO and EARLINET, Atmos. Chem. Phys., 15, 7127-7153, https://doi.org/10.5194/acp15-7127-2015, 2015.

Barkley, M. P., Kurosu, T. P., Chance, K., De Smedt, I., Van Roozendael, M., Arneth, A., Hagberg, D., and Guenther, A.: Assessing sources of uncertainty in formaldehyde air mass factors over tropical South America: Implications for top-down isoprene emission estimates, J. Geophys. Res.-Atmos., 117, D13304, https://doi.org/10.1029/2011JD016827, 2012.

Boersma, K. F., Eskes, H. J., and Brinksma, E. J.: Error analysis for tropospheric $\mathrm{NO}_{2}$ retrieval from space, J. Geophys. Res.-Atmos., 109, D04311, https://doi.org/10.1029/2003JD003962, 2004.

Boersma, K. F., Eskes, H. J., Dirksen, R. J., van der A, R. J., Veefkind, J. P., Stammes, P., Huijnen, V., Kleipool, Q. L., Sneep, M., Claas, J., Leitão, J., Richter, A., Zhou, Y., and Brunner, D.: An improved tropospheric $\mathrm{NO}_{2}$ column retrieval algorithm for 
the Ozone Monitoring Instrument, Atmos. Meas. Tech., 4, 19051928, https://doi.org/10.5194/amt-4-1905-2011, 2011.

Castellanos, P., Boersma, K. F., Torres, O., and de Haan, J. F.: OMI tropospheric $\mathrm{NO}_{2}$ air mass factors over South America: effects of biomass burning aerosols, Atmos. Meas. Tech., 8, 3831-3849, https://doi.org/10.5194/amt-8-3831-2015, 2015.

Chameides, W. L., Yu, H., Liu, S. C., Bergin, M., Zhou, X., Mearns, L., Wang, G., Kiang, C. S., Saylor, R. D., Luo, C., Huang, Y., Steiner, A., and Giorgi, F.: Case study of the effects of atmospheric aerosols and regional haze on agriculture: An opportunity to enhance crop yields in China through emission controls?, P. Natl. Acad. Sci. USA, 96, 13626-13633, https://doi.org/10.1073/pnas.96.24.13626, 1999.

Chimot, J., Vlemmix, T., Veefkind, J. P., de Haan, J. F., and Levelt, P. F.: Impact of aerosols on the OMI tropospheric $\mathrm{NO}_{2}$ retrievals over industrialized regions: how accurate is the aerosol correction of cloud-free scenes via a simple cloud model?, Atmos. Meas. Tech., 9, 359-382, https://doi.org/10.5194/amt-9359-2016, 2016.

Chimot, J., Veefkind, J. P., Vlemmix, T., de Haan, J. F., Amiridis, V., Proestakis, E., Marinou, E., and Levelt, P. F.: An exploratory study on the aerosol height retrieval from OMI measurements of the $477 \mathrm{~nm} \mathrm{O} \mathrm{O}_{2}-\mathrm{O}_{2}$ spectral band using a neural network approach, Atmos. Meas. Tech., 10, 783-809, https://doi.org/10.5194/amt-10-783-2017, 2017.

Colosimo, S. F., Natraj, V., Sander, S. P., and Stutz, J.: A sensitivity study on the retrieval of aerosol vertical profiles using the oxygen A-band, Atmos. Meas. Tech., 9, 1889-1905, https://doi.org/10.5194/amt-9-1889-2016, 2016.

Connor, B., Bösch, H., McDuffie, J., Taylor, T., Fu, D., Frankenberg, C., O’Dell, C., Payne, V. H., Gunson, M., Pollock, R., Hobbs, J., Oyafuso, F., and Jiang, Y.: Quantification of uncertainties in OCO-2 measurements of $\mathrm{XCO}_{2}$ : simulations and linear error analysis, Atmos. Meas. Tech., 9, 5227-5238, https://doi.org/10.5194/amt-9-5227-2016, 2016.

Crisp, D.: Measuring atmospheric carbon dioxide from space with the Orbiting Carbon Observatory-2 (OCO-2), SPIE Optical Engineering + Applications, 2015, San Diego, California, USA, Proceedings Volume 9607, Earth Observing Systems XX, 960702, https://doi.org/10.1117/12.2187291, 2015.

de Graaf, M., Stammes, P., and Aben, E. A. A.: Analysis of reflectance spectra of UV-absorbing aerosol scenes measured by SCIAMACHY, J. Geophys. Res.-Atmos., 112, D02206, https://doi.org/10.1029/2006JD007249, 2007.

de Graaf, M., Tilstra, L. G., Wang, P., and Stammes, P.: Retrieval of the aerosol direct radiative effect over clouds from spaceborne spectrometry, J. Geophys. Res.-Atmos., 117, D07207, https://doi.org/10.1029/2011JD017160, 2012.

de Haan, J. F.: DISAMAR Algorithm Description and Background Information, Royal Netherlands Meteorological Institute, De Bilt, the Netherlands, 2011.

Ding, S., Wang, J., and Xu, X.: Polarimetric remote sensing in oxygen $\mathrm{A}$ and $\mathrm{B}$ bands: sensitivity study and information content analysis for vertical profile of aerosols, Atmos. Meas. Tech., 9, 2077-2092, https://doi.org/10.5194/amt-9-2077-2016, 2016.

Dubovik, O., Holben, B., Eck, T. F., Smirnov, A., Kaufman, Y. J., King, M. D., Tanré, D., and Slutsker, I.: Variability of Absorption and Optical Properties of Key Aerosol Types Observed in Worldwide Locations, J.
Atmos. Sci., 59, 590-608, https://doi.org/10.1175/15200469(2002)059<0590:VOAAOP>2.0.CO;2, 2002.

Duncan, B., Prados, A., Lamsal, L., Liu, Y., Streets, D., Gupta, P., Hilsenrath, E., Kahn, R., Nielsen, J., Beyersdorf, A., Burton, S., Fiore, A., Fishman, J., Henze, D., Hostetler, C., Krotkov, N., Lee, P., Lin, M., Pawson, S., Pfister, G., Pickering, K., Pierce, R., Yoshida, Y., and Ziemba, L.: Satellite data of atmospheric pollution for U.S. air quality applications: Examples of applications, summary of data end-user resources, answers to FAQs, and common mistakes to avoid, Atmos. Environ., 94, 647-662, https://doi.org/10.1016/j.atmosenv.2014.05.061, 2014.

Eck, T. F., Holben, B. N., Dubovik, O., Smirnov, A., Goloub, P., Chen, H. B., Chatenet, B., Gomes, L., Zhang, X.-Y., Tsay, S.C., Ji, Q., Giles, D., and Slutsker, I.: Columnar aerosol optical properties at AERONET sites in central eastern Asia and aerosol transport to the tropical mid-Pacific, J. Geophys. Res.-Atmos., 110, D06202, https://doi.org/10.1029/2004JD005274, 2005.

Figueras i Ventura, J. and Russchenberg, H.: Towards a better understanding of the impact of anthropogenic aerosols in the hydrological cycle: IDRA, IRCTR drizzle radar, Phys. Chem. Earth A/B/C, 34, 88-92, https://doi.org/10.1016/j.pce.2008.02.038, 2009.

Hewson, W., Barkley, M. P., Gonzalez Abad, G., Bösch, H., Kurosu, T., Spurr, R., and Tilstra, L. G.: Development and characterisation of a state-of-the-art GOME-2 formaldehyde air-mass factor algorithm, Atmos. Meas. Tech., 8, 4055-4074, https://doi.org/10.5194/amt-8-4055-2015, 2015.

Hovenier, J. W. and Hage, J. I.: Relations involving the spherical albedo and other photometric quantities of planets with thick atmospheres, Astron. Astrophys., 214, 391-401, 1989.

Hsu, N., Herman, J., and Tsay, S.-C.: Radiative impacts from biomass burning in the presence of clouds during boreal spring in southeast Asia, Geophys. Res. Lett., 30, 1224, https://doi.org/10.1029/2002GL016485, 2003.

Hu, H., Hasekamp, O., Butz, A., Galli, A., Landgraf, J., Aan de Brugh, J., Borsdorff, T., Scheepmaker, R., and Aben, I.: The operational methane retrieval algorithm for TROPOMI, Atmos. Meas. Tech., 9, 5423-5440, https://doi.org/10.5194/amt-9-54232016, 2016.

Ingmann, I., Veihelmann, B., Langen, J., Lamarre, D., Stark, H., and Bazalgette Courrèges-Lacoste, G.: Requirements for the GMES Atmosphere Service and ESA's implementation concept: Sentinels-4/-5 and -5p, Remote Sensing Environ., 120, 58-69, https://doi.org/10.1016/j.rse.2012.01.023, 2012.

IPCC: The Core Writing Team Pachauri, R. K. and Meyer, L. A.: Climate Change 2014: Synthesis Report. Contribution of Working Groups I, II and III to the Fifth Assessment Report of the Intergovernmental Panel on Climate Change, IPCC, Geneva, Switzerland, available at: http://www.ipcc.ch/report/ar5/syr/ (last access: 7 November 2017), 2014.

Kacenelenbogen, M., Vaughan, M. A., Redemann, J., Hoff, R. M., Rogers, R. R., Ferrare, R. A., Russell, P. B., Hostetler, C. A., Hair, J. W., and Holben, B. N.: An accuracy assessment of the CALIOP/CALIPSO version 2/version 3 daytime aerosol extinction product based on a detailed multi-sensor, multi-platform case study, Atmos. Chem. Phys., 11, 3981-4000, https://doi.org/10.5194/acp-11-3981-2011, 2011.

Kim, M.-H., Kim, S.-W., Yoon, S.-C., and Omar, A. H.: Comparison of aerosol optical depth between CALIOP 
and MODIS-Aqua for CALIOP aerosol subtypes over the ocean, J. Geophys. Res.-Atmos., 118, 13241-13252, https://doi.org/10.1002/2013JD019527, 2013.

Kipling, Z., Stier, P., Johnson, C. E., Mann, G. W., Bellouin, N., Bauer, S. E., Bergman, T., Chin, M., Diehl, T., Ghan, S. J., Iversen, T., Kirkevåg, A., Kokkola, H., Liu, X., Luo, G., van Noije, T., Pringle, K. J., von Salzen, K., Schulz, M., Seland, Ø., Skeie, R. B., Takemura, T., Tsigaridis, K., and Zhang, K.: What controls the vertical distribution of aerosol? Relationships between process sensitivity in HadGEM3-UKCA and inter-model variation from AeroCom Phase II, Atmos. Chem. Phys., 16, 2221-2241, https://doi.org/10.5194/acp-16-2221-2016, 2016.

Koffi, B., Schulz, M., Bréon, F.-M., Griesfeller, J., Winker, D., Balkanski, Y., Bauer, S., Berntsen, T., Chin, M., Collins, W., Dentener, F., Diehl, T., Easter, R., Ghan, S., Ginoux, P., Gong, S., Horowitz, L., Iversen, T., Kirkevåg, A., Koch, D., Krol, M., Myhre, G., Stier, P., and Takemura, T.: Application of the CALIOP layer product to evaluate the vertical distribution of aerosols estimated by global models: AeroCom phase I results, J. Geophys. Res.-Atmos., 117, D10201, https://doi.org/10.1029/2011JD016858, 2012.

Krotkov, N. A., McClure, B., Dickerson, R. R., Carn, S. A., Li, C., Bhartia, P. K., Yang, K., Krueger, A. J., Li, Z., Levelt, P. F., Chen, $\mathrm{H}$., Wang, P., and $\mathrm{Lu}, \mathrm{D}$.: Validation of $\mathrm{SO}_{2}$ retrievals from the Ozone Monitoring Instrument over NE China, J. Geophys. Res.Atmos., 113, D16S40, https://doi.org/10.1029/2007JD008818, 2008.

Leitão, J., Richter, A., Vrekoussis, M., Kokhanovsky, A., Zhang, Q. J., Beekmann, M., and Burrows, J. P.: On the improvement of $\mathrm{NO}_{2}$ satellite retrievals - aerosol impact on the airmass factors, Atmos. Meas. Tech., 3, 475-493, https://doi.org/10.5194/amt-3475-2010, 2010.

Levelt, P. F., Hilsenrath, E., Leppelmeier, G. W., van den Oord, G. H. J., Bhartia, P. K., Tamminen, J., de Haan, J. F., and Veefkind, J. P.: Science Objectives of the Ozone Monitoring Instrument, IEEE T. Geosci. Remote, 44, 1199-1208, https://doi.org/10.1109/TGRS.2006.872336, 2006.

Levy, R. C., Mattoo, S., Munchak, L. A., Remer, L. A., Sayer, A. M., Patadia, F., and Hsu, N. C.: The Collection 6 MODIS aerosol products over land and ocean, Atmos. Meas. Tech., 6, 29893034, https://doi.org/10.5194/amt-6-2989-2013, 2013.

Lin, J.-T., Liu, M.-Y., Xin, J.-Y., Boersma, K. F., Spurr, R., Martin, R., and Zhang, Q.: Influence of aerosols and surface reflectance on satellite $\mathrm{NO}_{2}$ retrieval: seasonal and spatial characteristics and implications for $\mathrm{NO}_{x}$ emission constraints, Atmos. Chem. Phys., 15, 11217-11241, https://doi.org/10.5194/acp-15-112172015, 2015.

Liu, Z., Winker, D., Omar, A., Vaughan, M., Trepte, C., Hu, Y., Powell, K., Sun, W., and Lin, B.: Effective lidar ratios of dense dust layers over North Africa derived from the \{CALIOP\} measurements, J. Quant. Spectrosc. Ra., 112, 204213, https://doi.org/10.1016/j.jqsrt.2010.05.006, 2011.

Loeb, N. and Su, W.: Direct Aerosol Radiative Forcing Uncertainty Based on a Radiative Perturbation Analysis, J. Climate, 23, 5288-5293, https://doi.org/10.1175/2010JCLI3543.1, 2010.

Ma, J., Chen, Y., Wang, W., Yan, P., Liu, H., Yang, S., Hu, Z., and Lelieveld, J.: Strong air pollution causes widespread hazeclouds over China, J. Geophys. Res.-Atmos., 115, D18204, https://doi.org/10.1029/2009JD013065, 2010.
Martin, R.: Satellite remote sensing of surface air quality, Atmos. Environ., 42, 7823-7843, https://doi.org/10.1016/j.atmosenv.2008.07.018, 2008.

McComiskey, A., Schwartz, S., Schmid, B., Guan, H., Lewis, E., Ricchiazzi, P., and Ogren, J.: Direct aerosol forcing: Calculation from observables and sensitivities to inputs, J. Geophys. Res.Atmos., 113, D09202, https://doi.org/10.1029/2007JD009170, 2008.

Nanda, S., de Graaf, M., Sneep, M., de Haan, J. F., Stammes, P., Sanders, A. F. J., Tuinder, O., Veefkind, J. P., and Levelt, P. F.: Error sources in the retrieval of aerosol information over bright surfaces from satellite measurements in the oxygen A band, Atmos. Meas. Tech., 11, 161-175, https://doi.org/10.5194/amt-11161-2018, 2018.

NASA: NASA GoddardEarth Sciences Data and Information Services Center (GES DISC), available at: https://disc.gsfc. nasa.gov/uui/datasets/OMCLDO2_003/summary, last access: 7 November 2017

Palancar, G. G., Lefer, B. L., Hall, S. R., Shaw, W. J., Corr, C. A., Herndon, S. C., Slusser, J. R., and Madronich, S.: Effect of aerosols and $\mathrm{NO}_{2}$ concentration on ultraviolet actinic flux near Mexico City during MILAGRO: measurements and model calculations, Atmos. Chem. Phys., 13, 1011-1022, https://doi.org/10.5194/acp-13-1011-2013, 2013.

Park, S. S., Kim, J., Lee, H., Torres, O., Lee, K.-M., and Lee, S. D.: Utilization of $\mathrm{O}_{4}$ slant column density to derive aerosol layer height from a space-borne UV-visible hyperspectral sensor: sensitivity and case study, Atmos. Chem. Phys., 16, 1987-2006, https://doi.org/10.5194/acp-16-1987-2016, 2016.

Platt, U. and Stutz, J.: Differential Optical Absorption Spectroscopy (DOAS), Principles and Applications, Springer-Verlag, Berlin, Heidelberg, https://doi.org/10.1007/978-3-540-75776-4, 2008.

Proestakis, E., Amiridis, V., Marinou, E., Georgoulias, A. K., Solomos, S., Kazadzis, S., Chimot, J., Che, H., Alexandri, G., Binietoglou, I., Daskalopoulou, V., Kourtidis, K. A., de Leeuw, G., and van der A, R. J.: Nine-year spatial and temporal evolution of desert dust aerosols over South and East Asia as revealed by CALIOP, Atmos. Chem. Phys., 18, 1337-1362, https://doi.org/10.5194/acp-18-1337-2018, 2018.

Prospero, J. M. and Carlson, T. N.: Saharan Air Outbreaks Over the Tropical North Atlantic, in: Weather and Weather Maps. Contributions to Current Research in Geophysics, edited by: Liljequist, G. H., Birkhäuser, Basel, vol. 119, pp. 677-691, 1981.

Pueschel, R. F. and Livingston, J. M.: Aerosol spectral optical depths: Jet fuel and forest fire smokes, J. Geophys. Res.-Atmos., 95, 22417-22422, https://doi.org/10.1029/JD095iD13p22417, 1990.

Sanders, A. F. J., de Haan, J. F., Sneep, M., Apituley, A., Stammes, P., Vieitez, M. O., Tilstra, L. G., Tuinder, O. N. E., Koning, C. E., and Veefkind, J. P.: Evaluation of the operational Aerosol Layer Height retrieval algorithm for Sentinel-5 Precursor: application to $\mathrm{O}_{2}$ A band observations from GOME-2A, Atmos. Meas. Tech., 8, 4947-4977, https://doi.org/10.5194/amt-8-49472015, 2015.

Sarna, K. and Russchenberg, H. W. J.: Monitoring aerosol-cloud interactions at the CESAR Observatory in the Netherlands, Atmos. Meas. Tech., 10, 1987-1997, https://doi.org/10.5194/amt10-1987-2017, 2017. 
Sayer, A. M., Hsu, N. C., Bettenhausen, C., and Jeong, M.-J.: Validation and uncertainty estimates for MODIS Collection 6 "Deep Blue" aerosol data, J. Geophys. Res.-Atmos., 118, 7864-7872, https://doi.org/10.1002/jgrd.50600, 2013.

Schaul, T., Bayer, J., Wierstra, D., Sun, Y., Felder, M., Sehnke, F., Rückstieß, T., and Schmidhuber, J.: PyBrain, J. Mach. Learn. Res., 11, 746-746, http://www.pybrain.org/pages/download, 2010.

Spada, F., Krol, M. C., and Stammes, P.: McSCIA: application of the Equivalence Theorem in a Monte Carlo radiative transfer model for spherical shell atmospheres, Atmos. Chem. Phys., 6, 48234842, https://doi.org/10.5194/acp-6-4823-2006, 2006.

Torres, O., Tanskanen, A., Veihelmann, B., Ahn, C., Braak, R., Bhartia, P. K., Veefkind, P., and Levelt, P.: Aerosols and surface UV products from Ozone Monitoring Instrument observations: An overview, J. Geophys. Res.-Atmos., 112, D24S47, https://doi.org/10.1029/2007JD008809, 2007.

Torres, O., Ahn, C., and Chen, Z.: Improvements to the OMI near-UV aerosol algorithm using A-train CALIOP and AIRS observations, Atmos. Meas. Tech., 6, 3257-3270, https://doi.org/10.5194/amt-6-3257-2013, 2013.

Vaughan, M. A., Winker, D. M., and Powell, K. A.: CALIOP Algorithm Theoretical Basis Document, Part 2: Feature detection and layer properties algorithms, CALIOP ATBD PC-SCI-202 Part 2, Release 1.01, 87 pp., available at: http://www-calipso.larc.nasa. gov/resources/pdfs/PC-SCI-202_Part2_rev1x01.pdf (last access: 17 April 2018), 2005.

Veefkind, J. P., Aben, I., McMullan, K., Förster, H., de Vries, J., Otter, G., Claas, J., Eskes, H. J., de Haan, J. F., Kleipool, Q., van Weele, M., Hasekamp, O., Hoogeveen, R., Landgraf, J., Snel, R., Tol, P., Ingmann, P., Voors, R., Kruizinga, B., Vink, R., Visser, H., and Levelt, P. F.: TROPOMI on the ESA Sentinel-5 Precursor: A GMES mission for global observations of the atmospheric composition for climate, air quality and ozone layer applications, Remote Sensing Environ., 120, 70-83, https://doi.org/10.1016/j.rse.2011.09.027, 2012.

Veefkind, J. P., de Haan, J. F., Sneep, M., and Levelt, P. F.: Improvements to the $\mathrm{OMI} \mathrm{O}_{2}-\mathrm{O}_{2}$ operational cloud algorithm and comparisons with ground-based radar-lidar observations, Atmos. Meas. Tech., 9, 6035-6049, https://doi.org/10.5194/amt-96035-2016, 2016.

Vlemmix, T., Piters, A. J. M., Stammes, P., Wang, P., and Levelt, P. F.: Retrieval of tropospheric $\mathrm{NO}_{2}$ using the MAXDOAS method combined with relative intensity measurements for aerosol correction, Atmos. Meas. Tech., 3, 1287-1305, https://doi.org/10.5194/amt-3-1287-2010, 2010.

Wagner, T., Burrows, J. P., Deutschmann, T., Dix, B., von Friedeburg, C., Frieß, U., Hendrick, F., Heue, K.-P., Irie, H., Iwabuchi, H., Kanaya, Y., Keller, J., McLinden, C. A., Oetjen, H., Palazzi, E., Petritoli, A., Platt, U., Postylyakov, O., Pukite, J., Richter, A., van Roozendael, M., Rozanov, A., Rozanov, V., Sinreich, R., Sanghavi, S., and Wittrock, F.: Comparison of box-airmass-factors and radiances for Multiple-Axis Differential Optical Absorption Spectroscopy (MAX-DOAS) geometries calculated from different UV/visible radiative transfer models, Atmos. Chem. Phys., 7, 1809-1833, https://doi.org/10.5194/acp-7-18092007, 2007.

Wang, P., Tuinder, O. N. E., Tilstra, L. G., de Graaf, M., and Stammes, P.: Interpretation of FRESCO cloud retrievals in case of absorbing aerosol events, Atmos. Chem. Phys., 12, 90579077, https://doi.org/10.5194/acp-12-9057-2012, 2012.

Wilcox, E. M.: Direct and semi-direct radiative forcing of smoke aerosols over clouds, Atmos. Chem. Phys., 12, 139-149, https://doi.org/10.5194/acp-12-139-2012, 2012.

Winker, D.: Accounting for multiple scattering in retrievals from space lidar, in: 12th International Workshop on Lidar Multiple Scattering Experiments, Oberpfaffenhofen, Bavaria, Germany, 10-12 September 2002, SPIE.DigitalLibrary, 5059, 128-139, https://doi.org/10.1117/12.512352, 2003.

Winker, D., Vaughan, M., Omar, A., Hu, Y., Powell, K., Liu, Z., Hunt, W., and Young, S.: Overview of the CALIPSO Mission and CALIOP Data Processing Algorithms, J. Atmos. Ocean. Technol., 26, 2310-2323, https://doi.org/10.1175/2009JTECHA1281.1, 2009.

Winker, D. M., Tackett, J. L., Getzewich, B. J., Liu, Z., Vaughan, M. A., and Rogers, R. R.: The global 3-D distribution of tropospheric aerosols as characterized by CALIOP, Atmos. Chem. Phys., 13, 3345-3361, https://doi.org/10.5194/acp-133345-2013, 2013.

Wu, Y., Cordero, L., Gross, B., Moshary, F., and Ahmed, S.: Assessment of \{CALIPSO $\}$ attenuated backscatter and aerosol retrievals with a combined ground-based multi-wavelength lidar and sunphotometer measurement, Atmos. Environ., 84, 44-53, https://doi.org/10.1016/j.atmosenv.2013.11.016, 2014.

Wunch, D., Wennberg, P. O., Osterman, G., Fisher, B., Naylor, B., Roehl, C. M., O’Dell, C., Mandrake, L., Viatte, C., Kiel, M., Griffith, D. W. T., Deutscher, N. M., Velazco, V. A., Notholt, J., Warneke, T., Petri, C., De Maziere, M., Sha, M. K., Sussmann, R., Rettinger, M., Pollard, D., Robinson, J., Morino, I., Uchino, O., Hase, F., Blumenstock, T., Feist, D. G., Arnold, S. G., Strong, K., Mendonca, J., Kivi, R., Heikkinen, P., Iraci, L., Podolske, J., Hillyard, P. W., Kawakami, S., Dubey, M. K., Parker, H. A., Sepulveda, E., García, O. E., Te, Y., Jeseck, P., Gunson, M. R., Crisp, D., and Eldering, A.: Comparisons of the Orbiting Carbon Observatory-2 (OCO-2) $X_{\mathrm{CO}_{2}}$ measurements with TCCON, Atmos. Meas. Tech., 10, 2209-2238, https://doi.org/10.5194/amt10-2209-2017, 2017.

Xu, X., Wang, J., Wang, Y., Zeng, J., Torres, O., Yang, Y., Marshak, A., Reid, J., and Miller, S.: Passive remote sensing of altitude and optical depth of dust plumes using the oxygen $\mathrm{A}$ and $\mathrm{B}$ bands: First results from EPIC/DSCOVR at Lagrange-1 point, Geophys. Res. Lett., 44, 7544-7554, https://doi.org/10.1002/2017GL073939, 2017.

Xue, Y., Xu, H., Guang, J., Mei, L., Guo, J., Li, C., Mikusauskas, R., and He, X.: Observation of an agricultural biomass burning in central and east China using merged aerosol optical depth data from multiple satellite missions, Int. J. Remote Sens., 35, 59715983, https://doi.org/10.1080/2150704X.2014.943321, 2014.

Young, S. and Vaughan, M.: The Retrieval of Profiles of Particulate Extinction from Cloud-Aerosol Lidar Infrared Pathfinder Satellite Observations (CALIPSO) Data: Algorithm Description, J. Atmos. Ocean. Technol., 26, 1105-1119, https://doi.org/10.1175/2008JTECHA1221.1, 2009.

Yu, H., Kaufman, Y. J., Chin, M., Feingold, G., Remer, L. A., Anderson, T. L., Balkanski, Y., Bellouin, N., Boucher, O., Christopher, S., DeCola, P., Kahn, R., Koch, D., Loeb, N., Reddy, M. S., Schulz, M., Takemura, T., and Zhou, M.: A review of measurement-based assessments of the aerosol direct ra- 
diative effect and forcing, Atmos. Chem. Phys., 6, 613-666, https://doi.org/10.5194/acp-6-613-2006, 2006.

Zarzycki, C. M. and Bond, T. C.: How much can the vertical distribution of black carbon affect its global direct radiative forcing?, Geophys. Res. Lett., 37, L20807, https://doi.org/10.1029/2010GL044555, 2010. 